\title{
FCF/FEA/FSP
}

Programa de Pós-Graduação Interunidades em Nutrição Humana Aplicada - PRONUT

\section{ASPECTOS CLIINICOS E NUTRICIONAIS DE MULHERES NA PÓS-MENOPAUSA COM DOENÇA ARTERIAL CORONÁRIA}

\author{
APARECIDA DE OLIVEIRA
}

Dissertação para obtenção do grau de Mestre Orientador:

Prof. Titular Jorge Mancini Filho

VERSÃO REVISADA

SÃo PAULO

2003 
Autorizo, exclusivamente para fins acadêmicos e científicos, a reprodução total ou parcial desta dissertação, por processos fotocopiadores, Assinatura:

Data:

\section{Ficha Catalográfica}

Elaborada pela Divisão de Biblioteca e Documentação do Conjunto das Químicas da USP.

Oliveira, Aparecida de

O48a Aspectos clínicos e nutricionais de mulheres na pós-menopausa com doença arterial coronária / Aparecida de Oliveira. -- São Paulo, 2003.

$100 \mathrm{p}$.

Dissertação (mestrado) - Faculdade de Ciências Farmacêuticas da USP. Faculdade de Economia, Administração e Contabilidade da USP. Faculdade de Saúde Pública da USP. Curso Interunidades em Nutrição Humana Aplicada.

Orientador: Mancini Filho, Jorge

1. Nutrição 2. Menopausa 3. Doença coronária : Medicina 4. Hipertensão: Medicina 5. Diabetes : Medicina I. T. II. Mancini Filho, Jorge, orientador. 


\title{
ASPECTOS CLÍNICOS E NUTRICIONAIS DE MULHERES NA PÓS-MENOPAUSA COM DOENÇA ARTERIAL CORONÁRIA
}

\author{
Comissão Julgadora \\ Dissertação para obtenção do grau de Mestre
}

Prof. Titular Jorge Mancini Filho

Orientador/Presidente

\author{
Prof. Titular Jorge Mancini Filho \\ Orientador \\ Prof. Dr ${ }^{\mathrm{a}}$ Maria de Fátima Nunes Marucci \\ $1^{\circ}$ Examinador \\ Prof. Dr ${ }^{\mathrm{a}}$ Dulcinéia Saes Parra Abdalla \\ $2^{\circ}$ Examinador
}

São Paulo, 25 de junho de 2003 


\section{DedicatóRIA}

À Dona Conceição, minha mãe, pelo amor e dedicação, pela confortante e silenciosa presença nas noites em claro e quem, cuja lição de vida e simplicidade, serão meus exemplos até o fim dos meus dias 


\section{AgRADECIMENTOS}

* A DEUS, pela inesgotável bondade na minha vida, por cumprir os desejos do meu coração e pela reconfortante promessa "... esforça-te e tem bom ânimo... porque o Senhor teu Deus é contigo...” Josué cap. 1 ver. 9.

* Ao Prof. Titular Jorge Mancini Filho, pela orientação e paciência.

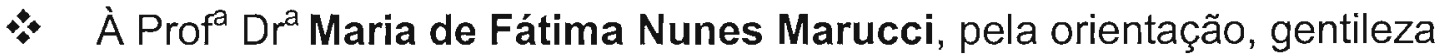
e por mostrar-me que "havia uma luz no fim do túnel".

Ao Serviço de Nutrição e Dietética do Instituto do Coração - HCFMUSP, na pessoa de sua diretora, Mitsue Isosaki, pela oportunidade.

Ao corpo docente do Curso de Nutrição e Dietética da Escola Técnica Estadual "Carlos de Campos", na pessoa de sua coordenadora, Professora Tuca, pela oportunidade, incentivo, motivação e pelo apoio nas minhas constantes ausências.

* Aos alunos do Curso de Nutrição e Dietética da Escola Técnica Estadual "Carlos de Campos", cujos "porquês" e vários "comos", ao longo desses anos, tornaram o processo de aprendizagem estimulante para mim.

* Às nutricionistas Adriana Ávila e Alessandra Macedo, da Seção de Atendimento Nutricional ao Paciente Externo do Serviço de Nutrição e Dietética do Instituto do Coração - HCFMUSP, pela coleta primária dos dados. 
* À equipe de nutricionistas da Seção de Atendimento Nutricional ao Paciente Internado do Serviço de Nutrição e Dietética do Instituto do Coração - HCFMUSP, pelo incentivo, apoio e por me suportarem nos momentos de incertezas e intensa ansiedade.

* Às nutricionistas Elisabeth Cardoso e Miyoko Nakasato, pelo incentivo, motivação e por serem os meus exemplos de determinação na busca ao conhecimento.

* Às nutricionistas Helenice Moreira da Costa, Viviane Claus, Camila Gracia, Lis Proença Vieira e Maria Rita Cardoso Albano, pela revisão do presente trabalho e pelas preciosas sugestões.

* A equipe da Unidade de Informações Médico-Hospitalares do Instituto do Coração - HCFMUSP, na pessoa do seu encarregado Wallace Fernandes, pela "incansável busca ao prontuário" e pelos momentos de descontração durante a coleta de dados.

* À estagiária curricular Ana Célia Salvadori, pela colaboração durante a coleta de dados e por me fazer crer que seria possivel a realização deste trabalho.

* Aos meus caros amigos, Myrley Soldera, Sérgio Jacondino de Oliveira, Keila e Marcelo Rosa Gomes, Marco Antônio Martinho Júnior, Alda Bernardinelli, Silmara Manzano Lima, Sheila Reis de Carvalho, Jefferson Nascimento Lima de Oliveira, Washington Marcelo Pereira e Família Domingues Andrade, pelo incentivo, motivação e pela inexplicável admiração.

A todas as pacientes envolvidas neste estudo e que desde então, fazem parte da minha história. 


\section{SUMÁRIO}

Página

Resumo

Abstract

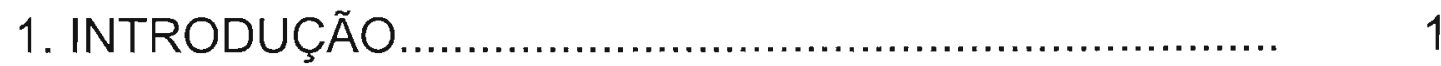

1.1 Climatério e menopausa..................................... 2

1.2. Obesidade...................................................... 6

1.3. Dislipidemias .............................................. 8

1.4. Hipertensão arterial sistêmica............................... 10

1.5. Diabetes melito............................................... 12

1.6. Síndrome da resistência à insulina......................... 15

1.7. Epidemiologia das doenças cardiovasculares............ 16

1.8. Doença arterial coronária.................................... 18

1.9. Custo das doenças ateroscleróticas....................... 22

1.10. Alimentação e a doença arterial coronária................ 23

Justificativa......................................................... 25

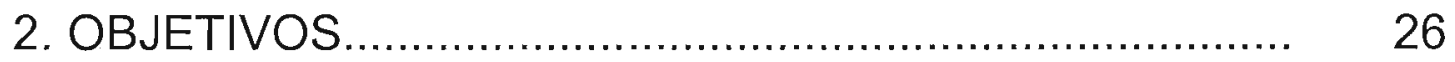

2.1. Geral........................................................... 26

2.2. Específicos............................................................ 26

3. PROCEDIMENTOS METODOLÓGICOS........................ 28

3.1. Delineamento do estudo................................................ 28

3.2. Casuística................................................... 28 
3.3. Aspectos éticos........................................................ 29

3.4. Métodos................................................................. 29

3.4.1. Dados antropométricos.............................................. 30

3.4.2. Avaliação do estado nutricional.................................. $\quad 30$

3.4.3. Descrição clínica......................................................... 31

3.4.4. Avaliação laboratorial.................................................. 31

3.4.5. Avaliação do consumo alimentar................................. 33

3.4.6. Tratamento estatístico............................................... 34

- Tamanho da amostra...................................................... 34

- Análise estatística.......................................................... 34

4. RESULTADOS ......................................................... 37

4.1. Caracterização da população de estudo...................... 37

4.2. Estado nutricional...................................................... 38

4.3. Descrição clínica............................................................ 41

4.4. Avaliação laboratorial..................................................... 45

4.5. Consumo alimentar ..................................................... 56

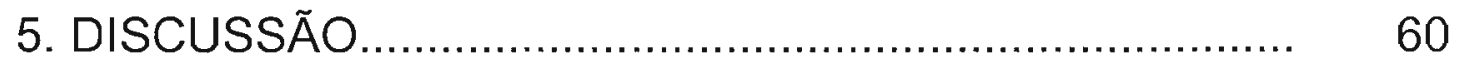

6. CONCLUSÕES ........................................................ 75

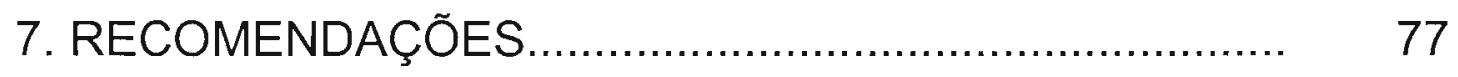

8. REFERÊNCIAS BIBLIOGRÁFICAS................................. 78 ANEXOS 


\section{LISTA DE FIGURAS}

Página

FIGURA 1 - Estado nutricional de acordo com o IMC..........

FIGURA 2 - Distribuição aceitável dos macronutrientes......

FIGURA 3 - Distribuição da população de estudo, segundo

o estado nutricional, de acordo com o IMC e grupo etário.

InCor - HCFMUSP. 1997-2001

FIGURA 4 - Correlação entre a idade e os índices de massa corpórea na população de estudo. InCor HCFMUSP. 1997-2001

FIGURA 5 - Correlação entre a idade e o peso na população de estudo. InCor - HCFMUSP. 1997-2001.

FIGURA 6 - Distribuição da população de estudo, segundo

o uso de hipolipemiantes e grupo etário. InCor HCFMUSP. 1997-2001

FIGURA 7 - Distribuição da população de estudo, segundo

a presença de diabetes melito (DM) e hipertensão arterial sistêmica (HAS) e grupo etário. InCor - HCFMUSP. 19972001.

FIGURA 8 - Distribuição da população de estudo, segundo 
níveis plasmáticos de colesterol total. InCor - HCFMUSP. $1997-2001$

FIGURA 9 - Distribuição da população de estudo, segundo níveis plasmáticos de LDL-c. InCor - HCFMUSP. 19972001

FIGURA 10 - Distribuição da população de estudo, segundo níveis plasmáticos de HDL-c. InCor - HCFMUSP. $1997-2001$

FIGURA 11 - Distribuição da população de estudo, segundo níveis plasmáticos de triacilgliceróis. InCor HCFMUSP. 1997-2001

FIGURA 12 - Correlação entre o IMC e os níveis plasmáticos de colesterol, no grupo etário entre 45 e 55 anos. InCor - HCFMUSP. 1997-2001

FIGURA 13 - Correlação entre o IMC e os níveis plasmáticos de LDL-c, no grupo etário entre 45 e 55 anos. InCor - HCFMUSP. 1997-2001

FIGURA 14 - Correlação entre o IMC e os níveis plasmáticos de HDL-c, no grupo etário entre 45 e 55 anos. InCor - HCFMUSP. 1997-2001 
FIGURA 15 - Correlação entre o IMC e os níveis plasmáticos de triacilgliceróis, no grupo etário entre 45 e 55 anos. InCor - HCFMUSP. 1997-2001

FIGURA 16 - Correlação entre o IMC e os níveis plasmáticos de colesterol, no grupo etário entre 55 e 65 anos. InCor - HCFMUSP. 1997-2001.

FIGURA 17 - Correlação entre o IMC e os níveis plasmáticos de LDL-c, no grupo etário entre 55 e 65 anos. InCor - HCFMUSP. 1997-2001. 50 FIGURA 18 - Correlação entre o IMC e os níveis plasmáticos de HDL-c, no grupo etário entre 55 e 65 anos. InCor - HCFMUSP. 1997-2001

FIGURA 19 - Correlação entre o IMC e os níveis plasmáticos de triacilgliceróis, no grupo etário entre 55 e 65 anos. InCor - HCFMUSP. 1997-2001 FIGURA 20 - Correlação entre o IMC e os níveis plasmáticos de colesterol, no grupo etário entre 65 e 75 anos. InCor - HCFMUSP. 1997-2001.............................

FIGURA 21 - Correlação entre o IMC e os níveis plasmáticos de LDL-c, no grupo etário entre 65 e 75 anos. 
InCor - HCFMUSP. 1997-2001

FIGURA 22 - Correlação entre o IMC e os níveis plasmáticos de HDL-c, no grupo etário entre 65 e 75 anos. InCor - HCFMUSP. 1997-2001 53

FIGURA 23 - Correlação entre o IMC e os niveis plasmáticos de triacilgliceróis, no grupo etário entre 65 e 75 anos. InCor - HCFMUSP. 1997-2001

FIGURA 24 - Correlação entre o IMC e os niveis plasmáticos de colesterol, no grupo etário $\geq 75$ anos. InCor - HCFMUSP. 1997-2001

FIGURA 25 - Correlação entre o IMC e os níveis plasmáticos de LDL-c, no grupo etário $\geq 75$ anos. InCor HCFMUSP. 1997-2001 54

FIGURA 26 - Correlação entre o IMC e os níveis plasmáticos de HDL-c, no grupo etário $\geq 75$ anos. InCor HCFMUSP. 1997-2001

FIGURA 27 - Correlação entre o IMC e os níveis plasmáticos de triacilgliceróis, no grupo etário $\geq 75$ anos. InCor - HCFMUSP. 1997-2001 55

FIGURA 28 - Distribuição da população de estudo, 
segundo a distribuição percentual do consumo de macronutrientes. InCor - HCFMUSP. 1997-2001.............. 56 FIGURA 29 - Correlação entre a idade e o total calórico da dieta na população estudada. InCor - HCFMUSP. 19972001

FIGURA 30 - Correlação entre a idade e o total de gorduras da dieta na população estudada. InCor HCFMUSP. 1997-2001. 


\section{LISTA DE TABELAS}

Página

TABELA 1 - Distribuição da população de estudo, segundo média, desvios-padrão e mediana de idade (em anos) e grupo etário. InCor - HCFMUSP. 1997-2001

TABELA 2 - Distribuição da população de estudo, segundo o estado nutricional, de acordo com o IMC. InCor HCFMUSP. 1997-2001

TABELA 3 - Distribuição da população de estudo segundo a média, desvios-padrão, mediana, valores mínimos e máximos de peso corporal e grupo etário. InCor HCFMUSP. 1997-2001

TABELA 4 - Distribuição da população de estudo, segundo a presença de diabetes melito e hipertensão arterial sistêmica. InCor - HCFMUSP. 1997-2001

TABELA 5 - Associação dos percentuais de presença de diabetes melito (isolada e associada) e estado nutricional, segundo o IMC, na população de estudo. InCor HCFMUSP. 1997-2001.

TABELA 6 - Associação dos percentuais de presença de 
hipertensão arterial sistêmica (isolada e associada) e estado nutricional, segundo o IMC, na população de estudo. InCor HCFMUSP. 1997-2001

TABELA 7 - Valores da média, desvios-padrão, mediana, mínimos e máximos de níveis plasmáticos de lípides na população de estudo. InCor - HCFMUSP. 1997-2001 ............

TABELA 8 - Distribuição dos valores da média, desviospadrão, mínimos e máximos de níveis plasmáticos de lípides na população de estudo, segundo o grupo etário. InCor HCFMUSP. 1997-2001

TABELA 9 - Valores da média, desvios-padrão, mediana, mínimos e máximos de calorias e fibras alimentares da população de estudo. InCor - HCFMUSP. 1997-2001

TABELA 10 - Valores da média, desvios-padrão, mínimos e máximos de calorias, macronutrientes e fibras alimentares da população de estudo, segundo o grupo etário. InCor HCFMUSP. 1997-2001 


\section{LISTA DE SIGLAS E ABREVIATURAS}

- ADA: American Diabetes Association

- AHA: American Heart Association

- DAC: Doença Arterial Coronária

- DRI: Dietary Reference Intakes (Ingestão Dietética de Referência)

- HDL-c: High Density Lipoprotein (Lipoproteína de Alta Densidade)

- IBGE: Instituto Brasileiro de Geografia e Estatística

- IMC: Índice de Massa Corpórea

- IMNA: Institute of Medicine of National Academies

- LDL-C: Low Density Lipoprotein (Lipoproteina de Baixa Densidade)

- MS: Ministério da Saúde

- NIH: National Institute of Health

- SBC: Sociedade Brasileira de Cardiologia

- SBD: Sociedade Brasileira de Diabetes

- SBH: Sociedade Brasileira de Hipertensão

- SBN: Sociedade Brasileira de Nefrologia

- WHO: World Health Organization 


\section{LISTA DE ANEXOS}

Página

ANEXO 1 - Aprovação da Comissão Científica e de Ética do Instituto do Coração do Hospital das Clínicas - FMUSP

ANEXO 2 - Aprovação da Comissão de Ética para Análise de Projetos de Pesquisa da Diretoria Clínica do Hospital das Clínicas - FMUSP

ANEXO 3 - Valores de referência dos lípides para indivíduos acima de 20 anos de idade. 


\section{Resumo}

Oliveira, A. Aspectos clínicos e nutricionais de mulheres na pósmenopausa com doença arterial coronária. São Paulo; 2003. [Dissertação de Mestrado - FCF-FEA-FSP/USP].

Objetivo: Avaliar os aspectos clínicos e nutricionais de mulheres na pósmenopausa com doença arterial coronária (DAC). Metodologia: Estudo transversal retrospectivo. Obtiveram-se dados do prontuário médico de 217 mulheres, na ocasião da primeira consulta no Ambulatório de Nutrição do InCor-HCFMUSP, referentes à idade, indice de massa corpórea, presença de diabetes melito (DM), hipertensão arterial sistêmica (HAS), uso de drogas hipolipemiantes, perfil lipêmico (colesterol e frações) e consumo alimentar habitual. Para os dados dietéticos utilizou-se impresso próprio. Resultados: A idade média observada foi 60,98 $\pm 9,23$ anos com prevalência de obesidade de $56 \%$. A presença de DM, HAS e uso de drogas hipolipemiantes foi observada em $46 \%, 80 \%$ e $73 \%$, respectivamente. Quanto ao perfil lipêmico, 44\% apresentavam altos níveis plasmáticos de colesterol. Em relação ao consumo alimentar, 59\% consumiam gorduras acima do limite superior aceitável e 95\% apresentavam consumo deficiente de fibras alimentares. Conclusões: As inadequações observadas podem refletir no surgimento de fatores de risco para DAC e, apesar de já ter desenvolvido a doença, esta população ainda cultiva os fatores que o levaram a ela. Faz-se necessária a ação multidisciplinar em Programas de Saúde da Mulher, abrangendo aspectos preventivos relacionados a DAC para, assim, melhorar a qualidade de vida nesta população.

Descritores: doença arterial coronária, menopausa, fatores de risco, obesidade, consumo de alimentos. 


\section{ABSTRACT}

Oliveira, A. Aspectos clínicos e nutricionais de mulheres na pósmenopausa com doença arterial coronária; [Clinical and nutritional aspects of postmenopausal women with coronary artery disease]. São Paulo (BR); 2003. [Dissertação de Mestrado - FCF-FEA-FSP/USP].

Objective: To assess clinical and nutritional aspects of postmenopausal women with coronary arterial disease (CAD). Methodology: Retrospective cross-sectional study. It was taken data of the clinical handbook of 217 women, in first interview at Heart Institute (InCor) - HCFMUSP. The variables studied were: age, body mass index, diagnoses to diabetes mellitus (DM), hypertension (Hy), using of lipid-lowering drugs, blood lipids (cholesterol and fractions) and food intake. It was used a specific tool for dietary data. Results: The mean age was $60,98 \pm 9,23$ years old with high prevalence of obesity (56\%). DM, Hy and using of lipid-lowering drugs were observed in $46 \%, 80 \%$ and $73 \%$, respectively. About blood lipids, $44 \%$ presented high serum cholesterol levels. About food intake, 59\% had intake fats up to acceptable superior limit and $95 \%$ presented low dietary fiber intake. Conclusions: This inadequates data can reflect in the sprouting of factors of risk for DAC and despite already has developed the illness this population still cultivates the factors that had taken it. It is necessary the action of a multidiscipline team in Health Programs for Women, to involve preventive aspects related to the DAC and to improve the quality of life of this population.

Keywords: coronary arterial disease, menopause, risk factors, obesity, food intake. 


\section{INTRODUÇÃo}

O século $X X$, além das inúmeras e velozes transformações, será lembrado como um marco da mudança do papel das mulheres na sociedade, pela evolução de suas conquistas na dimensão sócio-política, com evidências na sua inserção no mercado de trabalho e as modificações acarretadas na sua vida dentro do núcleo familiar (ROCHA et al. 2000).

Nos últimos anos, tem-se observado o aumento da população feminina no Brasil. Segundo dados do Instituto Brasileiro de Geografia e Estatística (IBGE), as mulheres detiveram as maiores taxas de crescimento populacional, entre 1991 e 2000 , em todas as regiões do país. No censo demográfico de 2000 , observou-se que $51 \%$ da população brasileira eram mulheres, das quais cerca de $17 \%$ apresentavam idade acima de 50 anos.

A maior longevidade das mulheres e suas conseqüências fazem parte de uma discussão específica relativa à mulher e ao seu período não reprodutivo (VERAS et al. 1987), levando à conclusão que, mesmo com um significativo aumento da expectativa de vida e longevidade, chegando aos 80 anos em alguns países, a data da instalação da menopausa manteve-se inalterada ao redor dos 50 anos (BYYNY \& SPEROFF 1996; NAMS 2002). 


\subsection{Climatério e menopausa}

A palavra climatério, derivado do grego "climakter", que significa escada, é usada para determinar uma fase de transição do período reprodutivo para o não reprodutivo no ciclo feminino (BIFFI 1991). É uma fase onde se observam manifestações de significativas mudanças biopsicossociais, sendo parte do processo de envelhecimento, iniciando-se em torno nos 35 anos (menacme) e estendendo-se até ao redor dos 65 anos (senectude) (HEGG et al. 1994).

Tem sido reconhecido, desde os primórdios dos tempos, que algumas mulheres ao chegarem no climatério, experimentam um estresse incomum e desconforto físico. Atualmente, é possível entender que essas "mudanças" marcam uma transformação gradual, iniciada no climatério, até o estado de hipoestrogenismo, acarretando implicações para o restante da vida (READ 2000).

Essa fase caracteriza-se por uma atividade ovariana decrescente, e subseqüente, deficiência e instabilidade hormonal, estando associada, mas nem sempre, a manifestações clínicas precoces, também conhecida como síndrome climatérica (MS 1994; ALDRIGHI 1996).

Embora a menopausa seja o termo mais divulgado, e muitas vezes, usado como sinônimo de climatério, ambos apresentam diferenças (HEGG et al. 1994). 
A menopausa representa a permanente ausência de menstruação, devido à perda da função folicular ovariana e pode ocorrer de forma espontânea ou induzida (NAMS 2002).

O termo "menopausa" é o ponto definido após 12 meses de amenorréia, subseqüentes ao último período menstrual (HEGG et al. 1994; NAMS 2002) e indica a possibilidade da função estrogênica dos ovários ter atingido ou estar atingindo o limiar dos efeitos patológicos nas mulheres sensiveis (HEGG et al. 1994).

No Ocidente, em média, a menopausa ocorre por volta dos 51,4 anos, com uma distribuição gaussiana de 40 a 58 anos (NAMS 2002).

Vários fatores podem antecipar ou retardar a ocorrência da menopausa natural.

Têm-se observado que o tabagismo, polimorfismos genéticos, nuliparidade, antidepressivos, exposição a substâncias tóxicas, radiação pélvica (usada no tratamento de câncer infantil) e epilepsia, especialmente em mulheres com maior freqüência de ataques, estão associados à ocorrência precoce da menopausa (ALDRIGUI 1996; NAMS 2002), enquanto que a multiparidade e a obesidade estão associadas à menopausa tardia (NAMS 2002). 
O estado de hipoestrogenismo acarreta repercussões negativas no psiquismo, no aparelho urogenital, nos fatores de coagulação, no metabolismo ósseo e lipêmico (HEGG et al. 1994).

- Psiquismo: As relações psicossociais sofrem influências de fatores somáticos, psicológicos, sócio-culturais, endócrinos e ambientais, que podem modificar o efeito que a transformação biológica têm no psiquismo e na situação social da mulher (HEGG et al. 1994).

- Aparelho urogenital: Os tecidos urogenitais são altamente sensíveis ao estrógeno e a sua diminuição ou ausência acarreta atrofia destes tecidos, levando à irritação da uretra, bem como à incontinência urinária (CUTSON \& MEULEMAN 2000).

- Fatores de coagulação: A redução dos estrógenos pode aumentar os fatores que facilitam o estado protrombótico, em especial pela maior concentração do fator VII, do fibrinogênio e do inibidor do ativador do plasminogênio (PAI-1), além de aumentar a formação de $L p(a)$, provocar a vasoconstrição e favorecer a agregação plaquetária (GEBARA 1996).

- Metabolismo ósseo: Os estrógenos causam maior atividade osteoblástica (GUYTON 1993) e a sua deficiência é a causa primária de osteoporose (CUTSON \& MEULEMAN 2000). 
- Metabolismo lipêmico: O hipoestrogenismo pode diminuir a resistência da lipoproteína de baixa densidade (LDL-c) aos fenômenos oxidativos, favorecendo a formação de LDL-c oxidadas, que possuem um potencial altamente aterogênico (BONDUKI et al. 2001).

A redução estrogênica favorece, ainda, o surgimento da obesidade central, a qual pode desencadear complicações metabólicas, tais como a dislipidemia, hipertensão arterial sistêmica e diabetes melito tipo 2, que auxiliam para o surgimento de aterosclerose (COLDITZ et al. 1987; GEBARA 1996; GIANNINI 1998; BONDUKI et al. 2001). 


\subsection{Obesidade}

A obesidade é uma desordem metabólica que afeta as pessoas dos países desenvolvidos e em desenvolvimento (ECKEL 1997). Pode ser definida como um desequilíbrio entre o valor calórico da dieta e o gasto energético, resultando em um acúmulo excessivo de tecido adiposo (ALDRIGHI 1996; PINOTTI \& FONSECA 1998).

A presença de obesidade é preocupante porque aumenta o risco para mortalidade (FELDMAN 1986; ECKEL 1997; NIH 1998; DESPRÉS et al. 2001; MONTILLA 2001), principalmente quando associada a dislipidemia, hipertensão arterial sistêmica, diabetes melito tipo 2 e doenças cardiovasculares (DESPRÉS et al. 2001).

Para a avaliação do estado nutricional, utiliza-se o Índice de Massa Corpórea (IMC), determinado pela relação entre peso (em kg) e a altura (em m) ao quadrado, inicialmente descrito por Quetelet em 1869 (WHO 1997; DESPRÉS et al. 2001).

A principal fragilidade desse índice é que não há distinção do aumento de gordura ou músculo, porém mostra correlação com medidas independentes da gordura corporal (grau de correlação: 0,7 a 0,8), além de ser prático e de baixo custo (CARVALHO 2002; PI-SUNYER 2003). 
Tem-se relatado um aumento progressivo na incidência de doenças crônicas com a elevação do IMC, mas tem-se observado que apesar do excesso de gordura, alguns individuos apresentam perfis metabólicos relativamente "normais", enquanto outros apresentam complicações metabólicas de risco cardiovascular (DESPRÉS et al. 2001).

Além do IMC, os indivíduos podem ser classificados de acordo com a distribuição de gordura corporal.

A obesidade andróide, também chamada de "obesidade do tipo maçã", na qual se observa um acúmulo de gordura na região abdominal, está relacionada com alto risco cardiovascular. Por sua vez, a obesidade ginecóide, caracterizada por um acúmulo de gordura nos quadris e, por isso, também chamada de "obesidade do tipo pêra", está relacionada com artroses e varizes (NIH 1998; CARVALHO 2002).

Na gênese da obesidade, os dois fatores fundamentais são os hábitos dietéticos inadequados, marcados por grande consumo de alimentos, sobretudo aqueles de alta densidade lipídica e energética, e a falta de atividade física, os quais podem sofrer influências genéticas e metabólicas que afetam o apetite, escolhas e preferências alimentares de cada um (MARTINEZ 2000). 


\subsection{Dislipidemias}

Resultados do estudo de Framingham (EUA), de estudos em outras cidades americanas e também em outros países (KANNEL et al. 1979; KEYS 1986; SIMONS 1986), demonstraram que os valores elevados da colesterolemia total e de LDL-c são indicativos de risco para ocorrência de eventos clínicos da doença arterial coronária (DAC) (ARMAGANIJAN \& BATLOUNI 2000).

A população apresenta baixa freqüência para a hipertriacilgliceridemia e, embora não esteja suficientemente claro o seu papel na gênese da placa aterosclerótica, é freqüente a associação desta alteração lipídica com aquelas ligadas à DAC, sobretudo na presença de obesidade e de baixos valores de lipoproteína de alta densidade (HDL-c) (ARMAGANIJAN \& BATLOUNI 2000).

Em relação a HDL-c, estudos prospectivos apontaram relação negativa entre os seus níveis plasmáticos e risco coronariano, em ambos os sexos, potencializado quando há simultaneidade entre baixos valores de HDL-c e elevados níveis de LDL-c (GIANNINI 1998; ARMAGANIJAN \& BATLOUNI 2000; AHA 2001).

Indivíduos obesos, com acúmulo de gordura visceral, tendem a apresentar hipertriacilgliceridemia e baixas concentrações de HDL-C (DESPRÉS et al. 2001; BONDUKI et al. 2001). 
Quanto às LDL-c, têm-se observado que, apesar dos indivíduos com obesidade abdominal, freqüentemente, apresentarem concentrações plasmáticas normais, há aumento da proporção de partículas pequenas e densas, que elevam o risco aterogênico nesses pacientes (NIH 1998; ARMAGANIJAN \& BATLOUNI 2000; AHA 2001). 


\subsection{Hipertensão arterial sistêmica}

A hipertensão arterial sistêmica pode ser conceituada como uma síndrome caracterizada por elevados níveis tensionais, associados a alterações hormonais e metabólicas e a fenômenos tróficos (hipertrofias cardíaca e vascular) (SBH, SBC, SBN 2002).

Quanto à sua prevalência, estima-se que $15 \%$ a $20 \%$ da população brasileira adulta apresentam hipertensão arterial (SBH, SBC, SBN 2002).

Estudos realizados em algumas cidades do Brasil indicam alta prevalência na população urbana adulta, entre $22,3 \%$ e $43,9 \%$, quando utilizado o critério de diagnóstico de hipertensão arterial de $\geq 140 \times 90 \mathrm{mmHg}$ (SBH, SBC, SBN 2002).

Além de apresentar alto custo social, sendo responsável por cerca de $40 \%$ dos casos de aposentadoria precoce e de absenteísmo no trabalho, a hipertensão arterial é considerada um dos principais fatores de risco de morbidade e mortalidade cardiovascular, cerca de $40 \%$ das mortes por acidente vascular encefálico e $25 \%$ daquelas por DAC (SBH, SBC, SBN 2002).

A hipertensão arterial acarreta injúria física direta sobre as células endoteliais, em pontos onde há bruscos desvios do fluxo sangüíneo, podendo provocar o aumento de penetração de LDL-c, por mecanismos não 
necessariamente dependentes de receptores; maior formação de LDL-c oxidada; liberação de fatores quimiotáxicos e mitogênicos, com atração e multiplicação de células musculares lisas na camada subendotelial, e, atração de monócitos para a parede, os quais se transformam em macrófagos, com intensa capacidade fagocitária sobre as LDL-c (GIANNINI 1998).

Quando os níveis pressóricos são iguais ou superiores a 140×90 $\mathrm{mmHg}$, ou sob medicação anti-hipertensiva, e estão associados ao tabagismo, obesidade, dislipidemia e diabetes melito, o risco para eventos cardiovasculares aumenta (AHA 2001). 


\subsection{Diabetes melito}

O diabetes melito é um dos mais importantes problemas mundiais de saúde e observa-se uma tendência de aumento de sua prevalência. As projeções indicam que no ano 2010 deverão existir 239 milhões de diabéticos em todo mundo (SBD 2000). Esse aumento deverá ocorrer devido, principalmente, à longevidade progressiva das populações e às modificações sócioculturais presentes na urbanização (SBD 2000).

No Brasil, o diabetes melito é a segunda doença de maior prevalência na população entre 35 e 64 anos e a primeira entre indivíduos com idade acima de 65 anos, em ambos os sexos (FUNDAÇÃO IBGE 2000).

O diabetes melito pode ser definido como uma síndrome de causa múltipla, decorrente da falta de insulina e/ou da sua incapacidade em exercer adequadamente seus efeitos metabólicos e é caracterizada pela presença de hiperglicemia crônica com distúrbios do metabolismo dos carboidratos, proteínas e lípides, com conseqüências vasculares e neurológicas a longo prazo (WHO 1999; SBD 2000).

O diabetes melito é classificado em: tipo 1, onde há destruição das células $\beta$ do pâncreas, geralmente ocasionando deficiência absoluta de insulina, de natureza auto-imune ou idiopática; tipo 2 , que varia de uma predominância de resistência insulínica a um defeito predominantemente 
secretório, com ou sem resistência à insulina, e; gestacional (SBD 2000; ADA 2002).

Alguns indivíduos manifestam intolerância à glicose, apresentando níveis elevados de glicemia, porém sem a caracterização do diagnóstico de diabetes melito, ou seja, estágios metabólicos intermediários entre a homeostase glicêmica normal e o diabetes melito propriamente dito (ADA 2002).

A doença cardiovascular é a principal responsável pela redução da sobrevida de pacientes diabéticos (PANZRAN 1987), sendo que o risco para aterosclerose é duas a três vezes maior em diabéticos do que em não diabéticos, independentemente de outros fatores de risco (OLIVEIRA et al. 1998; AHA 2001).

O aumento da mortalidade cardiovascular nos diabéticos está relacionado, além do próprio estado diabético, à associação de vários fatores de risco para doenças cardiovasculares, como obesidade, dislipidemia, hipertensão arterial, entre outros (OLIVEIRA et al. 1998; GAEDE et al. 1999).

Em individuos diabéticos, a hipertensão arterial é aproximadamente duas vezes mais freqüente do que na população geral (HYPERTENSION IN DIABETES STUDY GROUP 1993). 
A dislipidemia é um dos principais fatores de risco para doença cardiovascular em pacientes diabéticos, cuja influência é maior que a dos demais fatores (LEHTO et al. 1997).

A progressão da doença vascular no diabetes melito está relacionada aos mecanismos de disfunção endotelial e à influência de alterações hormonais (resistência à insulina), do metabolismo glicídico (hiperglicemia) e lipêmico, de citocinas, além de fatores ambientais (por exemplo, dietéticos) e genéticos (OLIVEIRA et al. 1998). 


\subsection{Síndrome da resistência à insulina}

A hipertensão arterial sistêmica e a obesidade, em especial a abdominal, freqüentemente estão associadas à dislipidemia e à intolerância à glicose, compondo a "síndrome metabólica" (SBH, SBC, SBN 2002; ADA 2002) também conhecida como síndrome da resistência à insulina, síndrome X, síndrome multimetabólica ou plurimetabólica, caracterizada pela resistência à insulina e pela hiperinsulinemia (SBH, SBC, SBN 2002).

A síndrome metabólica apresenta importante papel na gênese da doença cardiovascular (CARVALHO 2002), que corresponde a uma das principais causas de morte em um grande número de países desenvolvidos e em desenvolvimento (FERREIRA 2001). 


\subsection{Epidemiologia das doenças cardiovasculares}

Nos Estados Unidos, as doenças cardiovasculares são responsáveis por cerca de $40 \%$ de todas as mortes ou de uma a cada 2,5 mortes (AHA 2000).

$\mathrm{Na}$ América Latina, respondem por um terço de todas as mortes (TIMERMAN et al. 2001), enquanto que, no Brasil, são consideradas a principal causa de mortalidade na população adulta (LOTUFO 1998).

Em 1998, as doenças cardiovasculares foram responsáveis por $27 \%$ dos óbitos no país, e quando se excluem os óbitos por causas mal definidas e por violência, tal cifra aproxima-se de $40 \%$ (SBH, SBC, SBN 2002).

A tendência da mortalidade por doenças cardiovasculares tem diminuído nos países desenvolvidos desde a década de 60 (TIMERMAN et al. 2001). Nos Estados Unidos, a queda foi de aproximadamente $60 \%$ nas mortes por doença cerebrovascular e 53\% por DAC, no período de 1972 a 1994 (SBH, SBC, SBN 2002).

Entre as décadas de 30 e 90 observou-se, no Brasil, aumento do número de mortes por DAC (COSTA et al. 1996) com discreto declínio até 1996 (TIMERMAN et al. 2001; SBH, SBC, SBN 2002). 
No Brasil, observou-se declínio mais expressivo nas regiões Sul, Sudeste e Norte, em todos os grupos etários, para ambos os sexos, no período de 1979 a 1996 e aumento nas regiões Centro-Oeste e Nordeste, no mesmo período (TIMERMAN et al. 2001).

A causa desse declínio ainda não está bem esclarecida, mas as mudanças nos hábitos alimentares, a diminuição do tabagismo e o aumento da atividade física são apontados como responsáveis por essa queda (TIMERMAN et al. 2001).

Todavia, em 1998, na distribuição de óbitos por grupos de causas, segundo o sexo, destacaram-se as doenças do aparelho circulatório, em ambos os sexos. No Estado de São Paulo, desde o final dos anos 40, as doenças cardiovasculares persistem como importante causa de mortes (LOTUFO 1998; SECRETARIA DE SAÚDE DO ESTADO DE SÃO PAULO 1998). 


\subsection{Doença arterial coronária}

A DAC, dentre as doenças cardiovasculares, foi considerada como a principal causa de incapacitação e mortes, na população feminina norteamericana, após a menopausa (SCHENCK-GUSTATSON 1996). No Brasil, as taxas de mortalidade no sexo feminino, entre 45 e 65 anos, apresentamse maiores do que em países desenvolvidos (LOTUFO 1996).

A DAC é caracterizada por lesões com aspecto de placas (ateroma), que aparecem a partir da superfície interna do vaso sangüíneo, a íntima, como discretos nódulos, elevando-se acima do tecido (WILLIAMS 1997).

Baseando-se na estrutura microscópica e na composição histoquímica, pode se propor a classificação destas lesões em oito diferentes tipos (GIANNINI 2000):

- Tipo I (lesão inicial): Não há dano tecidual visível, mas observa-se o acúmulo de lipoproteínas na camada íntima e lípides em macrófagos, porém somente microscopicamente.

- Tipo II (estria gordurosa): Acúmulo de lipoproteínas na camada íntima, lípides em macrófagos e em células musculares lisas; quantidades suficientemente grandes que tornam as lesões visíveis a olho nu, mas não se identifica dano tecidual. Consideram-se dois subtipos: "Ila", potencialmente capazes de evoluir, observando-se espessamento adaptativo; e "l|b", menos susceptiveis a 
transformações, sendo resistentes à progressão e passíveis de regressão. As lesões do tipo Ila, bem como as lesões do tipo I, surgem nas duas primeiras décadas de vida, ou ainda, a partir da terceira década de vida (tipo Ila).

- Tipo III (pré-ateroma): Semelhante ao tipo II, porém com surgimento de depósitos extracelulares de lípides; evidência de dano e desordem tecidual. Surge a partir da terceira década de vida.

- Tipo IV (ateroma): Alterações do tipo Ila, acrescidas de massa de lípides extracelulares formando um núcleo de gordura ("lipid core"), com acentuado dano estrutural da íntima. Surgem também a partir da terceira década de vida.

- Tipo V (fibroateroma): Alterações do tipo IV, associadas ao desenvolvimento de camadas de colágeno e de células musculares lisas, que se colocam sobre o núcleo de lípides. Surgem a partir da quarta década de vida.

- Tipo VI (lesão complicada): Semelhantemente ao tipo $\mathrm{V}$, associada à presença de fissura ou erosão (tipo "Vla") e/ou a presença de hematoma ou hemorragia (tipo "VIb") e/ou a presença de material trombótico (tipo "VIc"). Surge a partir da quarta década de vida.

- Tipo VII (lesão calcificada): Qualquer lesão avançada com predomínio de cálcio; presença de acentuada deformidade estrutural.

- Tipo VIII (lesão fibrótica): Qualquer lesão avançada com composição predominante de colágeno; lípides em mínima quantidade ou 
ausentes. Surge a partir da quarta década de vida, assim como as lesões do tipo VII.

Estas placas podem ser instáveis, com predomínio de substâncias gordurosas, ou estáveis, com predomínio de colágeno ou cálcio (GIANNINI 2000).

Os eventos isquêmicos agudos estão, em geral, associados ao rompimento das placas instáveis, que induz a formação de trombo no local lesado, podendo levar à obstrução total do vaso, interrompendo o fluxo sangüíneo, com conseqüente manifestação aguda da doença isquêmica, de acordo com a região atingida (coração, cérebro, entre outras) (GIANNINI 1998).

A "Associação Americana de Cardiologia" (AHA 2001), por meio de diversos estudos, estabeleceu vários fatores de risco para a DAC e concluiu que, quanto maior o número de fatores de risco associados, maior a chance de apresentar a doença.

Além da obesidade, da hipertensão arterial, da dislipidemia e do diabetes melito, podemos agregar, ainda, o sexo, a idade, a história familiar de evento aterosclerótico prematuro e o tabagismo, como fatores de maior risco para o desenvolvimento de DAC (AHA 2001). 
As mulheres, em acréscimo a estes fatores de risco, apresentam outros exclusivos, como o uso de contraceptivos orais e a menopausa (WENGER 1996; CARVALHO FILHO et al. 1996; JACOBSEN et al. 1999) que, pela perda da "proteção estrogêrica", parece ser responsável pela incidência e, conseqüente, mortalidade por DAC após a menopausa, tornando-a uma fase biológica de risco na vida da mulher (CHIAMVIMONT \& STERINBERG 1998; TRÉMOLIIĖRES et al. 1999). 


\subsection{Custo das doenças ateroscleróticas}

O custo das doenças cardiovasculares, no Brasil, tem crescido exponencialmente nas últimas décadas, sendo que em 2000, foram responsáveis pelo principal gasto de recursos públicos em hospitalizações e foram a terceira causa de permanência intra-hospitalar (MS 2001).

As conseqüências clínicas da doença aterosclerótica representam um custo expressivo nos gastos em saúde (SBC 2001).

Atualmente, é expressivo o percentual de pacientes submetidos a procedimentos de revascularização percutânea e cirúrgica, com um custo médio por procedimento em torno de $\mathrm{R} \$ 3.800,00$ a $\mathrm{R} \$ 5.800,00$ (SBC 2001).

Têm-se observado que esse aumento nos custos na área de saúde é mundial e diversos países estão buscando racionalizar e otimizar os recursos disponíveis, com o risco eminente de que parte da população não se beneficie pela falta ou distribuição inadequada de recursos (LESSA et al. 1996). 


\subsection{Alimentação e a doença arterial coronária}

A alimentação pode exercer papel fundamental na determinação do aparecimento de doenças, pois se tem observado que grande parte das doenças crônicas têm um componente nutricional importante (WEISBURGUER 2000).

As práticas alimentares inadequadas estão associadas à obesidade, a alterações nos niveis plasmáticos de lípides, a aterogênese, a incidência e a mortalidade por doença cardiovascular (STONE et al. 1996).

Observam-se, na sociedade atual, as conseqüências dos excessos alimentares na aterogênese (CARVALHO FILHO et al. 1996), os quais têm evidenciado a relação entre as características qualitativas da dieta (rica em gorduras, principalmente as saturadas, e colesterol, ricas em açúcares refinados e sódio) e a ocorrência de DAC (PORRINI 1991; COSTA et al. 2000).

Existe forte correlação entre a ingestão de ácidos graxos saturados (ácido láurico, mirístico e palmítico) com o nível de colesterol plasmático. Têm-se observado que, em países com alto índice de DAC, o consumo de gordura animal predomina sobre as demais (KEYS 1986).

Quanto ao consumo do colesterol dietético, têm-se observado que o mesmo eleva o colesterol total e LDL-c sangüineos, mas em menor 
extensão do que os ácidos graxos saturados que, quando associados, é possivel observar um efeito sinérgico sobre as LDL-c, pois inibem a síntese e atividade dos receptores de LDL-c, elevando os níveis de LDL-c circulante, favorecendo a sua oxidação (KRUMMEL 1998).

Têm-se observado que modificações dietéticas favorecem a redução da colesterolemia com conseqüente diminuição da freqüência de eventos coronarianos (TURPEINEN et al. 1979; HJERMANN et al. 1981).

Como medida de intervenção para redução da hipercolesterolemia, além da restrição de alimentos ricos em colesterol e o incentivo ao uso de proporções adequadas de gorduras saturadas, monoinsaturadas e polinsaturadas, têm-se estimulado o consumo de fibras alimentares (GIANNINI 1993).

As fibras alimentares são polissacarídeos e, por suas características químicas, podem ser classificadas como solúveis e insolúveis (POURCHETCAMPOS 1998).

As fibras alimentares solúveis, quando consumidas em quantidades adequadas, parecem reduzir os níveis de colesterol total e LDL-c, provavelmente pelo efeito seqüestrador dos ácidos biliares no intestino, o que diminui o seu retorno ao fígado (FONSECA et al. 1999). 


\section{JUSTIFICATIVA}

O conhecimento dos aspectos clínicos e nutricionais de mulheres na fase pós-menopausa, com DAC, pode proporcionar dados que permitam uma adequada intervenção nutricional, contribuindo, dessa forma, para a prevenção da doença em mulheres nesta fase da vida. 


\section{ObJetivos}

\subsection{Geral}

Avaliar os aspectos clínicos e nutricionais de mulheres na fase pósmenopausa com DAC.

\subsection{Específicos}

- Avaliar o estado nutricional;

- Identificar a presença de diabetes melito e hipertensão arterial;

- Verificar o uso de hipolipemiantes e avaliar o perfil lipêmico;

- Verificar o consumo alimentar;

- Observar a distribuição percentual dos macronutrientes;

- Correlacionar a idade e os índices de massa corpórea;

- Correlacionar a idade e o peso;

- Correlacionar a idade e os lípides sangüíneos;

- Correlacionar a idade e o valor calórico total da dieta;

- Correlacionar a idade e o consumo de macronutrientes e de fibras alimentares;

- Correlacionar a idade, os índices de massa corpórea e o perfil lipêmico;

- Associar a presença de diabetes melito e o estado nutricional;

- Associar a presença de hipertensão arterial sistêmica e o estado nutricional, e; 
- Observar diferenças significativas entre os grupos etários em relação ao peso, valor calórico total da dieta, consumo de macronutrientes e fibras alimentares. 


\section{Procedimentos metodológicos}

\subsection{Delineamento do estudo}

Estudo transversal, com utilização de dados secundários.

\subsection{Casuística}

A população de estudo foi selecionada entre todas as pacientes do sexo feminino que foram atendidas individualmente, entre Janeiro de 1997 e Dezembro de 2001, pela equipe de nutricionistas do ambulatório de nutrição do Serviço de Nutrição e Dietética do Instituto do Coração do Hospital das Clínicas da Faculdade de Medicina da Universidade de São Paulo (InCor HCFMUSP).

Foram incluídas no estudo mulheres, (1) em primeira consulta com o nutricionista; (2) com DAC diagnosticada por cineangiocoronariografia; (3) com ausência de ciclos menstruais de, no mínimo, um ano; (4) sem anterior revascularização do miocárdio, e; (5) com disponibilidade dos dados necessários à pesquisa.

Por se tratar de dados secundários, é importante ressaltar que, primariamente os mesmos foram coletados pela equipe de nutricionistas responsáveis pelo atendimento nutricional no referido ambulatório, durante o período proposto, por meio de rotina padronizada de atendimento 
estabelecida previamente pelo Serviço e, portanto, não foram utilizados questionários ou entrevistas específicas para este estudo.

Cabe ainda informar, que o atendimento neste ambulatório pode ser individualizado ou em grupo, conforme a necessidade clínica do paciente e/ou disponibilidade do Serviço.

\subsection{Aspectos éticos}

O presente estudo foi avaliado e aprovado pela Comissão Científica e de Ética do Instituto do Coração - SDC 2112/02/119 na sessão 4/17/02/17 de 17/10/2002 (Anexo 1) e pela Comissão de Ética para Análise de Projetos de Pesquisa - CAPPesq da Diretoria Clínica do Hospital das Clínicas da Faculdade de Medicina da Universidade de São Paulo - Protocolo de Pesquisa $n^{\circ}$ 891/02 em sessão de 20/11/2002 (Anexo 2), atendendo às normas regulamentadoras da Resolução $n^{\circ} 196$ de 10 de outubro de 1996 do Conselho Nacional de Saúde.

É importante ressaltar que, após o projeto de pesquisa ser submetido à apreciação pelos Comitês de Ética, anteriormente mencionados, optou-se pela modificação do título, devido ao objetivo proposto.

\subsection{Métodos}

Foram coletados, do prontuário médico, dados antropométricos, clínicos, laboratoriais e dietéticos. 


\subsubsection{Dados antropométricos}

As medidas de peso e altura foram obtidas por meio de balança com estadiômetro acoplado, da marca Filizola ${ }^{\circledR}$ modelo PL-150 (Brasil), com sensibilidade de $0,05 \mathrm{~kg}$ e $0,05 \mathrm{~m}$, respectivamente.

Na verificação do peso, era solicitado à paciente que permanecesse com roupas, que não pudessem comprometer a mensuração, sem sapatos e o mais imóvel possível.

Quanto à altura, solicitava-se que, sem sapatos, a paciente permanecesse, com os braços estendidos lateralmente ao corpo, com os pés juntos e que os calcanhares, omoplata, nádegas e a região occipital da cabeça permanecessem o mais próximo possivel do estadiômetro. A posição da cabeça favoreceu a verificação do "Plano de Frankfurt" (DE HOOG 1998).

\subsubsection{Avaliação do estado nutricional}

Optou-se por avaliar o estado nutricional segundo o IMC (WHO 1997; DE HOOG 1998; DESPRÉS et al. 2001), posteriormente à obtenção das medidas de peso e altura, utilizando os critérios propostos pela WHO (1997), conforme a FIGURA 1. 
FIGURA 1 - Estado nutricional de acordo com o IMC

\begin{tabular}{|c|c|}
\hline Baixo Peso & $<18,5 \mathrm{~kg} / \mathrm{m}^{2}$ \\
Normal & $18,5-24,9 \mathrm{~kg} / \mathrm{m}^{2}$ \\
Pré-obesidade & $25,0-29,9 \mathrm{~kg} / \mathrm{m}^{2}$ \\
Obesidade Grau I & $30,0-34,9 \mathrm{~kg} / \mathrm{m}^{2}$ \\
Obesidade Grau II & $35,0-39,9 \mathrm{~kg} / \mathrm{m}^{2}$ \\
Obesidade Grau III & $\geq 40 \mathrm{~kg} / \mathrm{m}^{2}$ \\
\hline
\end{tabular}

Fonte: World Health Organization. Report of a WHO Consultation on Obesity. Obesity preventing and managing the global epidemic. Geneva; 1997.

\subsubsection{Descrição clínica}

Verificou-se, no prontuário médico, o uso de hipolipemiantes e a presença de hipertensão arterial e de diabetes melito, mediante diagnóstico clínico constatado pelo médico.

Para a verificação do uso de hipolipemiantes observou-se a indicação de estatinas, resinas de troca e fibratos, que são medicamentos utilizados na redução de LDL-c, colesterol e triacilgliceróis endógenos em adultos, respectivamente (SBC 2001).

\subsubsection{Avaliação laboratorial}

Foram obtidos, do prontuário médico, os valores de triacilgliceróis, colesterol total, HDL-c e LDL-c, imediatamente anterior à data da primeira consulta com o nutricionista.

As coletas e análises laboratoriais foram executadas, como procedimento de rotina, pelo Laboratório de Análises Clínicas do Instituto do 
Coração do Hospital das Clínicas da Faculdade de Medicina da Universidade de São Paulo, por meio das seguintes técnicas:

- Todas as amostras de sangue foram coletadas por punção venosa periférica, após período de jejum de doze horas.

- Para a avaliação dos triacilgliceróis, utilizou-se o método enzimático automatizado e para o colesterol total e HDL-c, o método colorimétricoenzimático.

- Para a determinação da LDL-c, utilizou-se a Fórmula de Friedewald (SBC 2001): LDL-C $=$ colesterol total $-(H D L-c-$ triacilgliceróis/5). Esta fórmula foi válida para triacilgliceróis $<400 \mathrm{mg} / \mathrm{dL}$ e, quando estes eram maiores que $400 \mathrm{mg} / \mathrm{dL}$, utilizava-se o método enzimático e colorimétrico.

Posteriormente, os valores observados foram comparados com os valores de referência específicos (SBC 2001), os quais encontram-se em anexo (Anexo 3), conforme as seguintes categorias:

- Colesterol: "desejável", "limite máximo" e "alto".

- LDL-c: "ótimo", "desejável", "limítrofe", "alto" e "muito alto".

- HDL-c: "baixo" e "alto".

- Triacilgliceróis: "ótimo", "limítrofe", "alto" e "muito alto". 


\subsubsection{Avaliação do consumo alimentar}

Os dados de consumo alimentar foram obtidos do formulário "Anamnese e Diagnóstico" (CARDOSO et al. 1997) (Anexo 4), elaborado pelo Serviço de Nutrição e Dietética do Instituto do Coração do Hospital das Clínicas da Faculdade de Medicina da Universidade de São Paulo, utilizado rotineiramente durante o atendimento nutricional no Ambulatório, no qual são registrados os dados de consumo alimentar qualitativamente, por meio de questionário de freqüência de consumo alimentar e, quantitativamente, pelo consumo alimentar habitual de um dia, por meio da história dietética adaptada do método de Burke (CARDOSO et al. 1997).

A quantificação foi realizada sob forma de medidas caseiras, relatadas pela paciente na ocasião da consulta com o nutricionista do Ambulatório.

Foram verificados o valor calórico total da dieta e o consumo quantitativo de carboidratos, proteínas, gorduras e fibras alimentares, os quais foram processados pelo software "Virtual Nutri: Sistema de Análise Nutricional" (PHILIPPI 1996), que fornece a composição centesimal dos alimentos ("in natura", processados ou de preparações culinárias).

A distribuição dos macronutrientes foi verificada conforme a distribuição aceitável destes nutrientes e de acordo com o "Institute of Medicine", para indivíduos adultos, conforme a FIGURA 2: 
FIGURA 2: Distribuição aceitável dos macronutrientes

\begin{tabular}{|c|c|}
\hline Macronutrientes & Distribuição \\
\hline Carboidratos & $45-65 \%$ \\
Proteínas & $10-35 \%$ \\
Gorduras & $20-35 \%$ \\
\hline
\end{tabular}

Fonte: INSTITUTE OF MEDICINE (2002)

Quanto às fibras alimentares, considerou-se adequado o consumo entre 20 e 30g/dia (KRAUSS et al. 2000).

\subsubsection{Tratamento estatístico}

- Tamanho da amostra:

Em um estudo (PEETERS et al. 2001), observou-se que a proporção de DAC entre mulheres na pós-menopausa estava próxima de $50 \%$. Por meio da teoria da inferência estatística, com um intervalo de confiança de 95\%, o tamanho da amostra foi estimada em 196 pacientes.

\section{- Análise estatística:}

Os dados foram armazenados em banco de dados do "Excel 2000 Microsoft $\circledast$ Office" (Microsoft ${ }^{\circledR}$ Corporation, EUA) e, posteriormente, analisados.

As variáveis quantitativas (idade, peso, IMC, triacilgliceróis, colesterol total, HDL-c, LDL-c, calorias, consumo de carboidratos, proteínas, gorduras 
e fibras alimentares) foram analisadas por meio da observação dos valores mínimos e máximos, do cálculo de médias, desvios-padrão e medianas.

Para as variáveis qualitativas (uso de hipolipemiantes, categoria de estado nutricional, presença de diabetes melito e de hipertensão arterial) calcularam-se as freqüências absolutas e relativas.

Para observar diferença significativa entre os grupos etários em relação ao peso e a hipótese de igualdade de médias das categorias de estado nutricional foi utilizada a análise de variância a um fator (ROSNER 1986) e o teste não paramétrico de Kruskal-Wallis (ROSNER 1986) para observar diferenças entre os grupos etários em relação ao consumo de fibras alimentares.

As comparações múltiplas foram realizadas pelo teste de Bonferroni (ROSNER 1986) e o de Dunn (HOLLANDER \& WOLF 1973).

Para se avaliar a correlação entre duas variáveis, foi utilizado o coeficiente de correlação de Pearson (ROSNER 1986).

Para testar a hipótese de igualdade de médias entre dois grupos independentes (idade e diabetes melito e idade e hipertensão arterial), foi utilizado o teste $t$ de Student (ROSNER 1986). 
A comparação entre proporções foi feita por meio do teste Quiquadrado (ROSNER 1986).

O nível de significância utilizado para os testes foi $5 \%$. 


\section{RESULTADOS}

\subsection{Caracterização da população de estudo}

Durante o periodo de estudo foram avaliadas 217 mulheres.

A média de idade da população estudada foi $60,98 \pm 9,23$ anos, com mediana de 61 anos e idade mínima e máxima de 45 anos e 86 anos, respectivamente.

O grupo etário de maior prevalência foi o de 55 a 65 anos (35\%). A TABELA 1 demonstra a distribuição da média, desvios-padrão e mediana de idade (em anos), em cada grupo etário.

TABELA 1 - Distribuição da população de estudo, segundo média, desviospadrão e mediana de idade (em anos) e grupo etário. InCor - HCFMUSP. 1997-2001.

\begin{tabular}{ccccc}
\hline $\begin{array}{c}\text { Grupo etário } \\
\text { (em anos) }\end{array}$ & $\begin{array}{c}\text { Número de } \\
\text { Observações }\end{array}$ & $\begin{array}{c}\text { Média } \\
\text { (em anos) }\end{array}$ & $\begin{array}{c}\text { Desvios-Padrão } \\
\text { (em anos) }\end{array}$ & $\begin{array}{c}\text { Mediana } \\
\text { (em anos) }\end{array}$ \\
\hline 45 |-- 55 & 62 & 49,94 & 2,61 & 50 \\
55 |-- 65 & 76 & 59,63 & 3,02 & 60 \\
65 |- 75 & 64 & 69,13 & 2,89 & 69 \\
$\geq 75$ & 15 & 78,73 & 2,89 & 78
\end{tabular}




\subsection{Estado nutricional}

Em relação ao estado nutricional, constatou-se que a média de IMC foi de $31,37 \pm 6,34 \mathrm{~kg} / \mathrm{m}^{2}$, a categoria de "pré-obesidade" foi a mais prevalente (30\%) e o grupo etário entre 45 e 55 anos foi o que apresentou maior prevalência de obesidade (65\%). A distribuição da população de estudo, segundo o estado nutricional de acordo com o IMC e segundo o grupo etário, encontra-se na TABELA 2 e FIGURA 3, respectivamente.

TABELA 2 - Distribuição da população de estudo, segundo o estado nutricional, de acordo com o IMC. InCor - HCFMUSP. 1997-2001.

\begin{tabular}{lcc}
\hline Índice de Massa Corpórea & FA & FR \\
\hline Baixo peso & 0 & $0 \%$ \\
Normal & 31 & $14 \%$ \\
Pré-obesidade & 66 & $30 \%$ \\
Obesidade grau I & 62 & $29 \%$ \\
Obesidade grau II & 41 & $19 \%$ \\
Obesidade grau III & 17 & $8 \%$ \\
\hline Total & 217 & $100 \%$ \\
\hline
\end{tabular}

FA: Freqüência Absoluta; FR: Freqüência Relativa

FIGURA 3 - Distribuição da população de estudo, segundo o estado nutricional, de acordo com o IMC e grupo etário. InCor - HCFMUSP. 19972001.

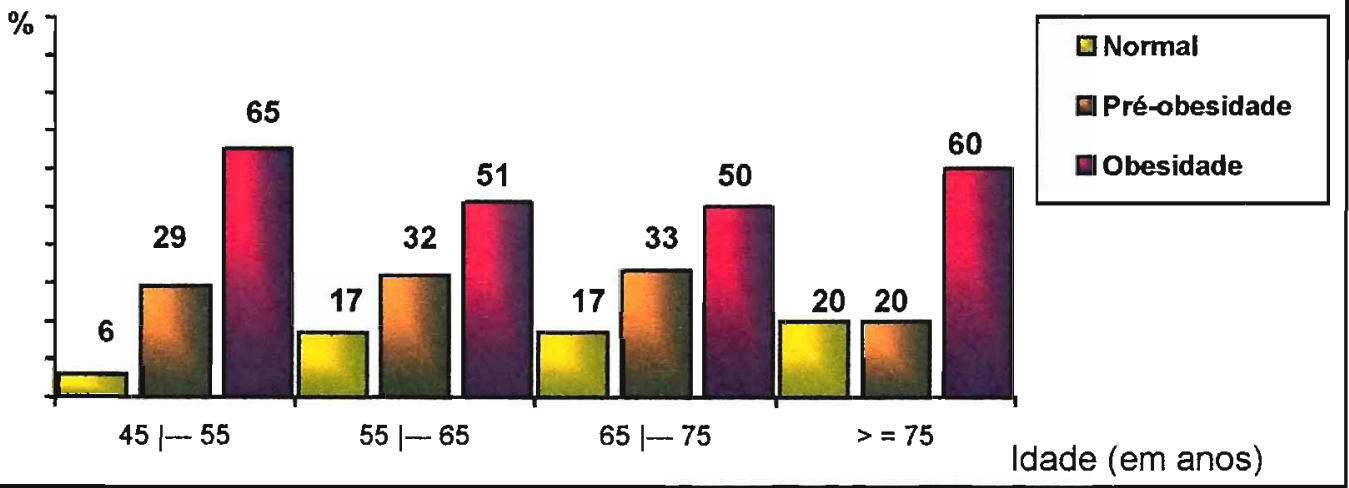


Observou-se correlação negativa e significativa entre a idade e os índices de massa corpórea $(r=-0,1682 ; p=0,0131)$, ou seja, quanto maior a idade, menor o IMC, conforme a FIGURA 4.

FIGURA 4 - Correlação entre a idade e os índices de massa corpórea na população de estudo. InCor - HCFMUSP. 1997-2001.

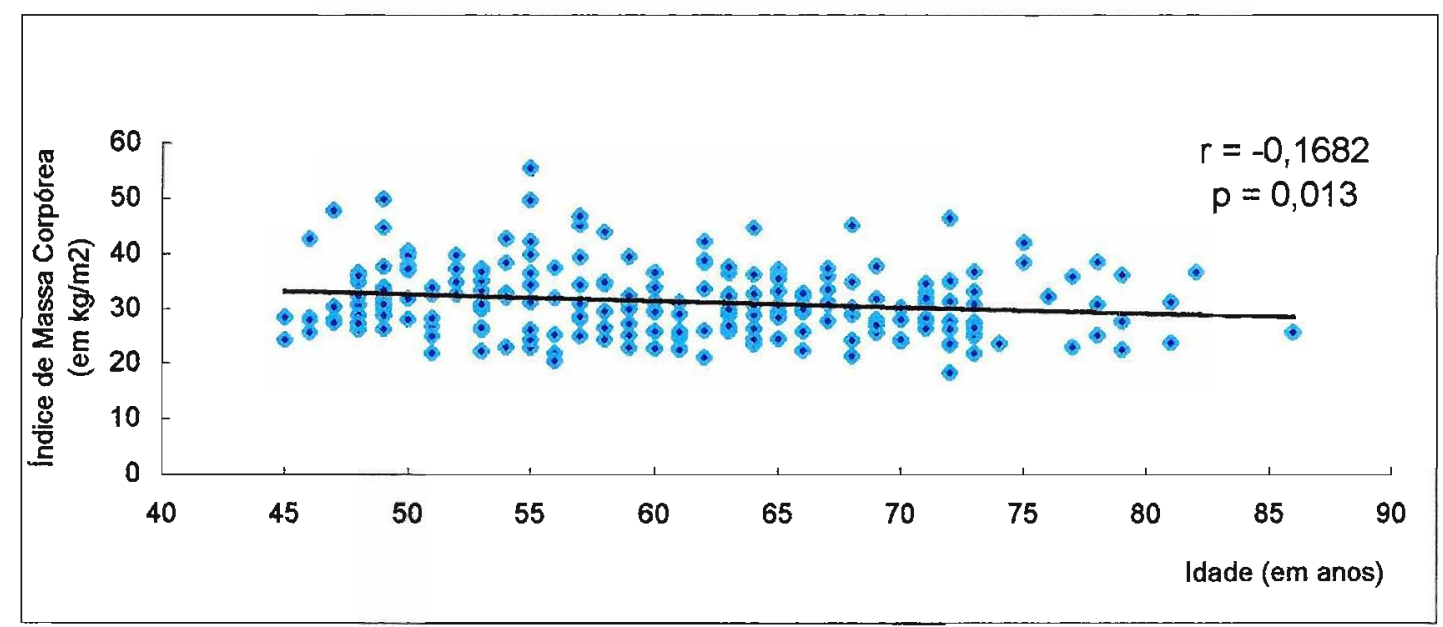

Ao avaliar isoladamente os valores de peso, observaram-se valores médios de $73,66 \pm 16,39 \mathrm{~kg}$.

O grupo etário no qual foi observada a maior média de peso corporal foi o de 45 e 55 anos. A TABELA 3 demonstra a distribuição da população de estudo segundo a média, desvios-padrão, mediana, valores mínimos e máximos de peso corporal e grupo etário. 
TABELA 3 - Distribuição da população de estudo segundo a média, desviospadrão, mediana, valores mínimos e máximos de peso corporal e grupo etário. InCor - HCFMUSP. 1997-2001.

\begin{tabular}{cccccc}
\hline $\begin{array}{c}\text { Grupo etário } \\
\text { (em anos) }\end{array}$ & $\begin{array}{c}\text { Média } \\
(\mathrm{em} \mathrm{kg})\end{array}$ & $\begin{array}{c}\text { Desvios- } \\
\text { padrão }(\mathrm{em} \mathrm{kg})\end{array}$ & $\begin{array}{c}\text { Mediana } \\
(\mathrm{em} \mathrm{kg})\end{array}$ & $\begin{array}{c}\text { Mínimo } \\
(\mathrm{em} \mathrm{kg})\end{array}$ & $\begin{array}{c}\text { Máximo } \\
(\mathrm{em} \mathrm{kg})\end{array}$ \\
\hline $45 \mid--55$ & 78,12 & 15,60 & 75,65 & 46,70 & 117,30 \\
$55 \mid--65$ & 73,56 & 19,09 & 68,30 & 44,40 & 140,00 \\
$65 \mid--75$ & 70,23 & 13,59 & 69,25 & 47,30 & 112,70 \\
$\geq 75$ & 70,43 & 12,14 & 66,20 & 53,70 & 92,00 \\
\hline
\end{tabular}

Por meio da análise de variância a um fator, observou-se que há diferença significativa entre os grupos etários em relação ao peso ( $p=$ 0,0450). Por meio do teste de Bonferroni, observou-se que o grupo com idade entre 45 e 55 anos difere do grupo com idade entre 65 e 75 anos ( $p<$ $0,05)$.

Correlacionou-se a idade e o peso, o que demonstrou haver correlação negativa e significativa, assim, quanto maior a idade, menor o peso da população estudada $(r=-0,2186 ; p=0,0012)$ (FIGURA 5).

FIGURA 5 - Correlação entre a idade e o peso na população de estudo. InCor - HCFMUSP. 1997-2001.

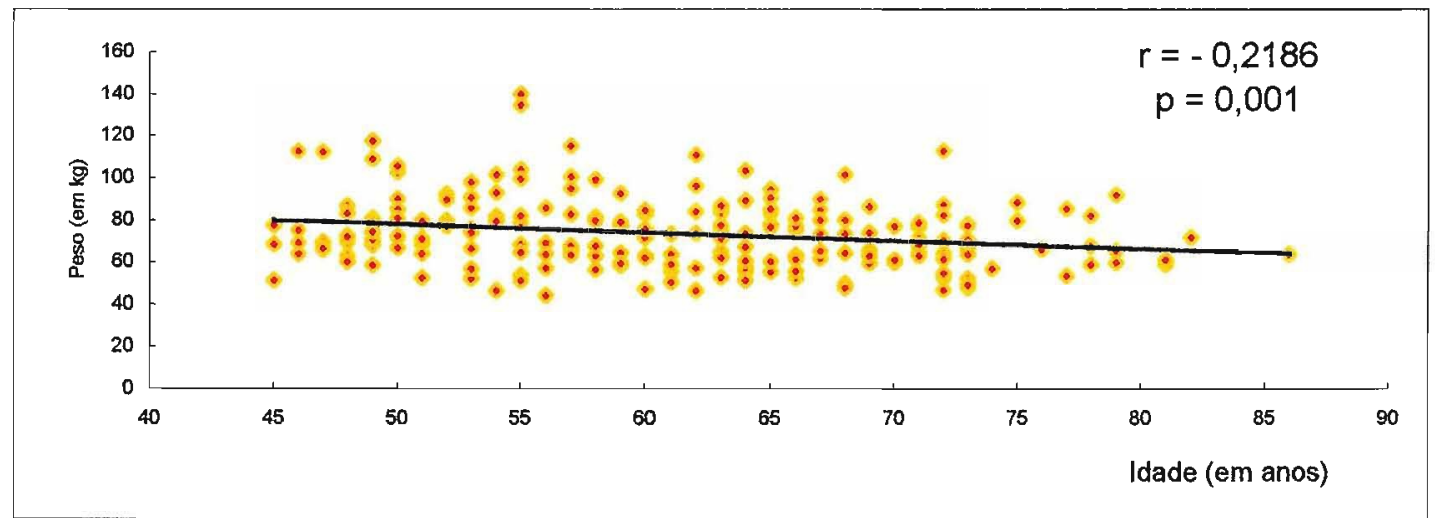




\subsection{Descrição clínica}

Observou-se que $73 \%$ da população de estudo estavam sob tratamento com hipolipemiantes, sendo que no grupo etário maior ou igual a 75 anos a prevalência foi maior (87\%). A distribuição da população de estudo, segundo o uso de hipolipemiantes e grupo etário encontra-se na FIGURA 6.

FIGURA 6 - Distribuição da população de estudo, segundo o uso de hipolipemiantes e grupo etário. InCor - HCFMUSP. 1997-2001.

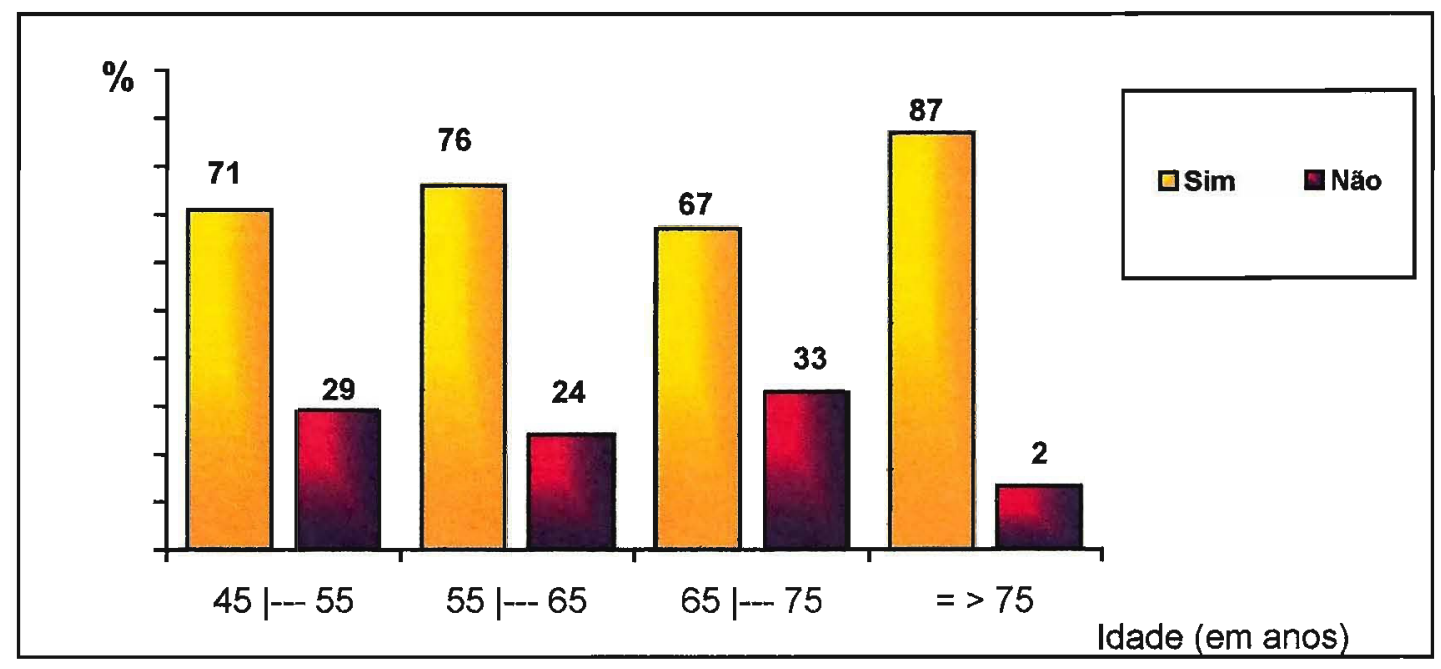

Observou-se, também, que somente $8 \%$ apresentavam diabetes melito e $42 \%$ hipertensão arterial sistêmica, porém, $38 \%$ apresentam a associação entre estes dois diagnósticos, conforme demonstra a TABELA 4.

A distribuição da população estudada, segundo a presença de diabetes melito e hipertensão arterial e grupo etário encontra-se na FIGURA 7. 
As pacientes com diagnóstico de diabetes melito situavam-se em idades entre 45 e $78(58,07 \pm 8,43)$ anos e aquelas sem diabetes melito em idades entre 45 e $86(63,42 \pm 9,20)$ anos, esta diferença é significativa (test t de Student, $p<0,001)$. Assim, o grupo com diabetes melito é significativamente mais jovem.

Não houve diferença significativa em relação à presença de hipertensão arterial sistêmica (teste t de Student, $p=0,910$ ).

TABELA 4 - Distribuição da população de estudo, segundo a presença de diabetes melito e hipertensão arterial sistêmica. InCor - HCFMUSP. 19972001.

\begin{tabular}{lccc}
\hline \multicolumn{1}{c}{ Variável } & FA & FR \\
\hline Ausente & 27 & $12 \%$ \\
Diabetes melito & 17 & $8 \%$ \\
Hipertensão arterial sistêmica & 91 & $42 \%$ \\
Diabetes melito e Hipertensão arterial sistêmica & 82 & $38 \%$ \\
\hline Total & 217 & $100 \%$ \\
\hline
\end{tabular}

FA: Freqüência Absoluta; FR: Freqüência Relativa 
FIGURA 7 - Distribuição da população de estudo, segundo a presença de diabetes melito (DM) e hipertensão arterial sistêmica (HAS) e grupo etário. InCor - HCFMUSP. 1997-2001.

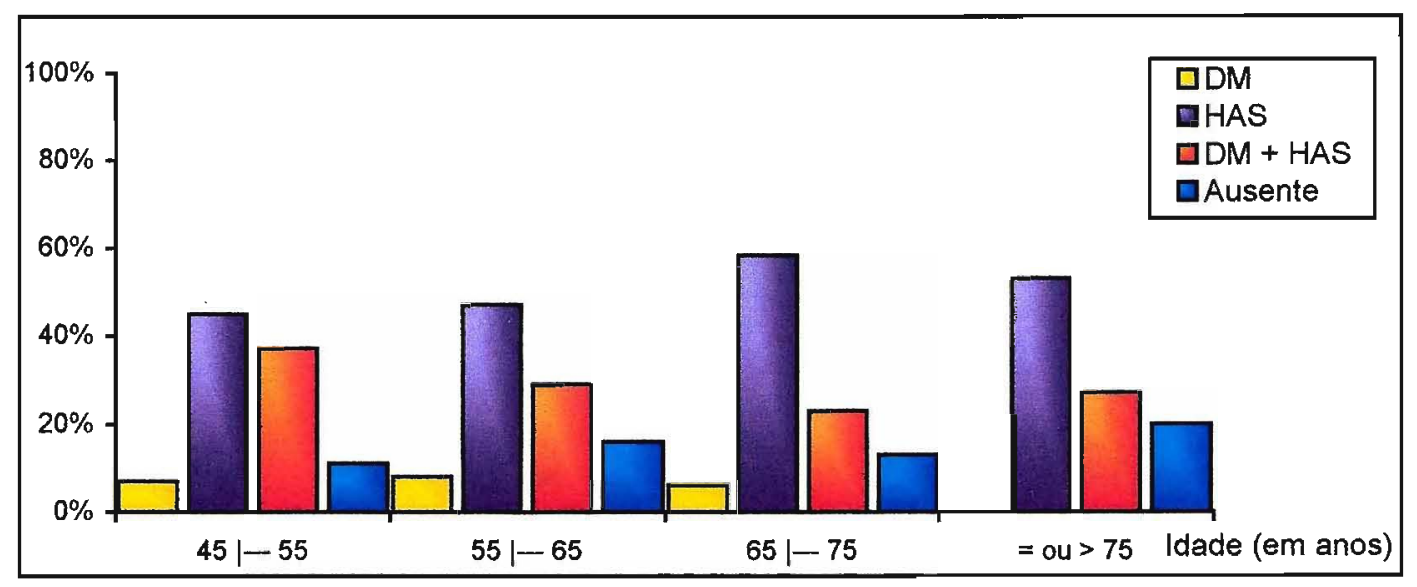

Observou-se, também, que houve diferença significativa entre os percentuais de presença de diabetes melito e o estado nutricional, de acordo com o IMC. As categorias "obesidade graus I, II e III" não apresentaram diferença significativa ( $p=0,0993)$, as categorias "normal" e "pré-obesidade" diferem entre si $(p=0,0213)$. Os grupos de obesidade diferem dos outros dois $(p<0,001)$, conforme a TABELA 5.

TABELA 5 - Associação dos percentuais de presença de diabetes melito (isolada e associada) e estado nutricional, segundo o IMC, na população de estudo. InCor - HCFMUSP. 1997-2001.

\begin{tabular}{llccc}
\hline Variável & Categoria & FA & FR & P $^{*}$ \\
\hline & Normal & 4 & 12,90 & \\
& Pré-obesidade & 25 & 37,88 & \\
Estado Nutricional & Obesidade Grau I & 34 & 54,84 & $<0,001$ \\
& Obesidade Grau II & 22 & 53,66 & \\
& Obesidade Grau III & 14 & 82,35 &
\end{tabular}

FA: Freqüência Absoluta; FR: Freqüência Relativa

*. nível descritivo de probabilidade do teste Qui-quadrado 
Por sua vez, não se observou diferença significativa entre os percentuais da presença de hipertensão arterial sistêmica e estado nutricional, conforme a TABELA 6.

TABELA 6 - Associação dos percentuais de presença de hipertensão arterial sistêmica (isolada e associada) e estado nutricional, segundo o IMC, na população de estudo. InCor - HCFMUSP. 1997-2001.

\begin{tabular}{llcccc}
\hline Variável & Categoria & FA & FR & $\mathrm{p}^{*}$ \\
\hline & Normal & 24 & 77,42 & \\
& Pré-obesidade & 49 & 74,24 & \\
Estado Nutricional & Obesidade Grau I & 49 & 79,03 & $<0,439$ \\
& Obesidade Grau II & 36 & 87,80 & \\
& Obesidade Grau III & 15 & 88,24 &
\end{tabular}

FA: Freqüência Absoluta; FR: Freqüência Relativa

*: nível descritivo de probabilidade do teste Qui-quadrado 


\subsection{Avaliação laboratorial}

A TABELA 7 demonstra a análise descritiva dos perfis lipêmicos observados na população estudada.

TABELA 7 - Valores da média, desvios-padrão, mediana, mínimos e máximos de níveis plasmáticos de lípides na população de estudo. InCor HCFMUSP. 1997-2001.

\begin{tabular}{lccccc}
\hline \multicolumn{1}{c}{ Variável $(\mathrm{mg} / \mathrm{dL})$} & Média & $\mathrm{DP}^{*}$ & Mediana & Mínimo & Máximo \\
\hline Colesterol Total & 234,23 & 43,23 & 232 & 132 & 380 \\
HDL-c & 43,53 & 10,26 & 43 & 20 & 72 \\
LDL-c & 156,43 & 43,40 & 151 & 24 & 391 \\
Triacilgliceróis & 171,80 & 82,80 & 157 & 11 & 691 \\
\hline *DP: desvios-padrão. & & & &
\end{tabular}

As FIGURAS 8, 9, 10 e 11 demonstram a distribuição da população segundo níveis plasmáticos de colesterol, LDL-c, HDL-c e triacilgliceróis, respectivamente.

FIGURA 8 - Distribuição da população de estudo, segundo níveis plasmáticos de colesterol total. InCor - HCFMUSP. 1997-2001.

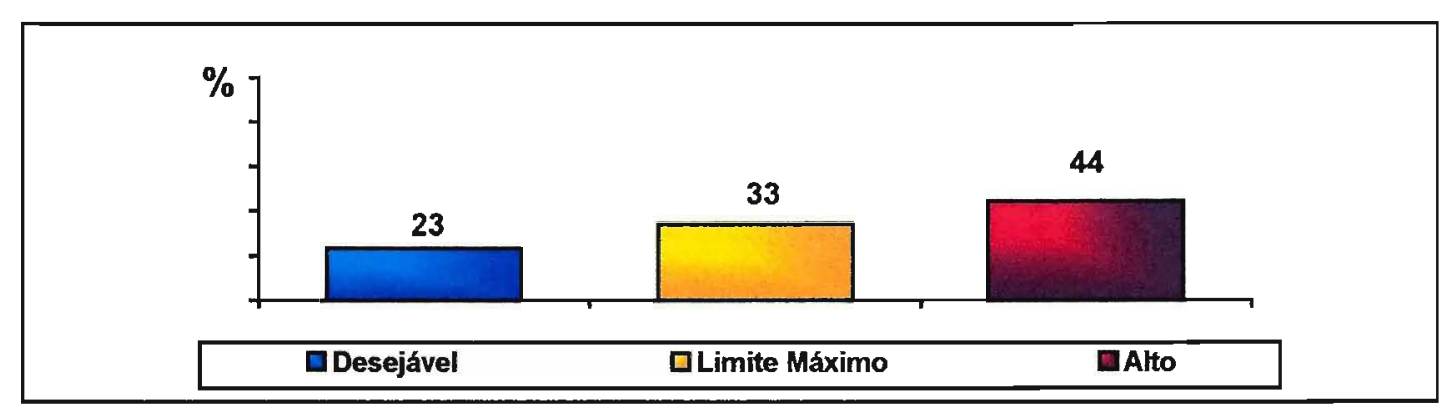


FIGURA 9 - Distribuição da população de estudo, segundo níveis plasmáticos de LDL-C. InCor - HCFMUSP. 1997-2001.

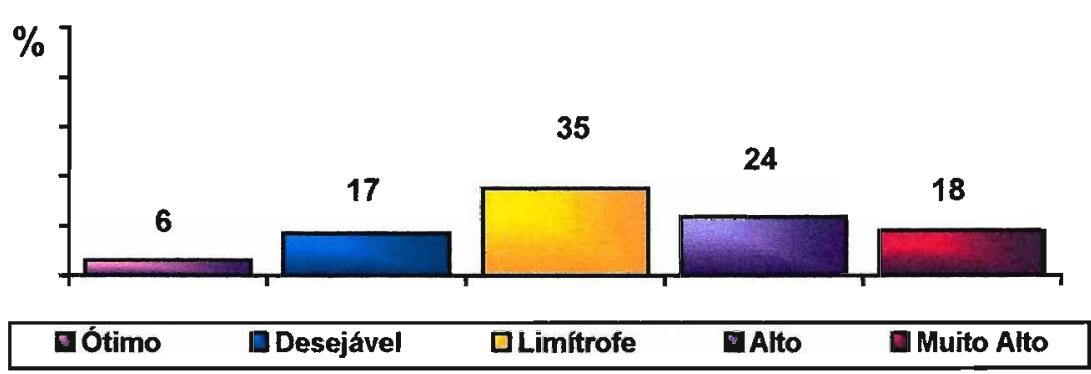

FIGURA 10 - Distribuição da população de estudo, segundo níveis plasmáticos de HDL-c. InCor - HCFMUSP. 1997-2001.

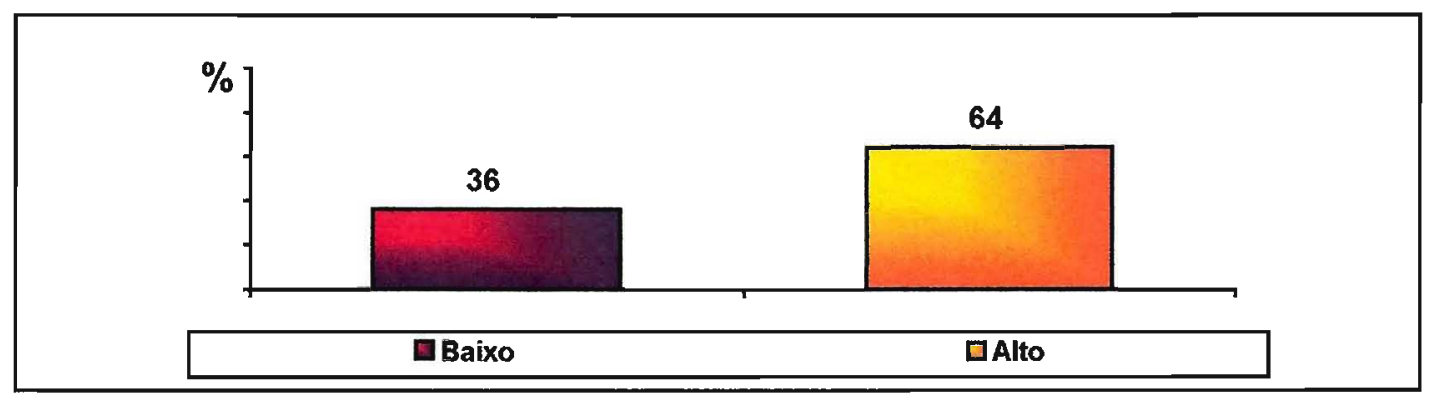

FIGURA 11 - Distribuição da população, segundo niveis plasmáticos de triacilgliceróis. InCor - HCFMUSP. 1997-2001.

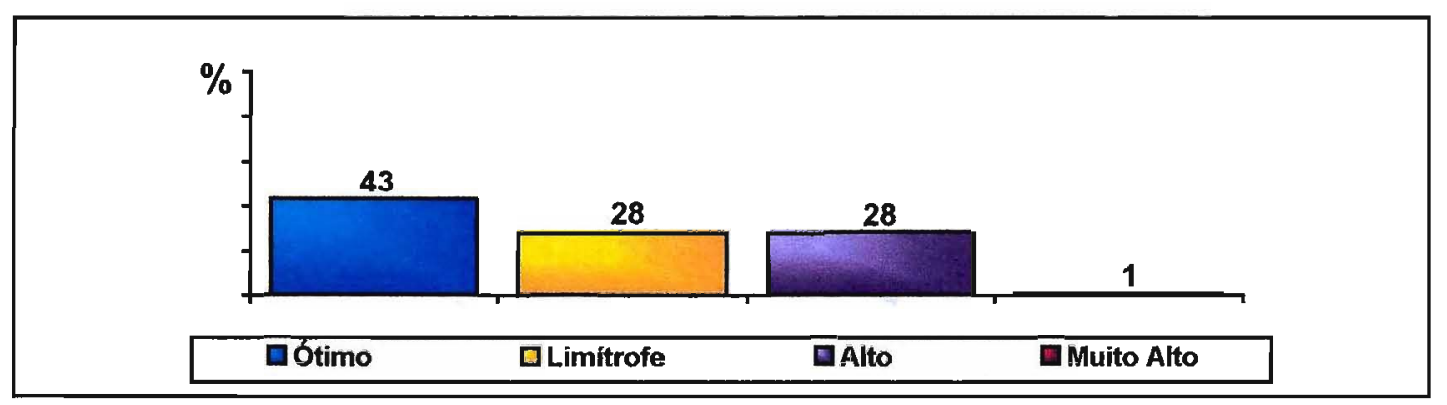

Não foi observada correlação entre a idade e os níveis de colesterol total $(r=0,07818 ; p=0,2514)$, LDL-c $(r=0,02837 ; p=0,6777)$, HDL-c $(r=$ $0,06053 ; p=0,3749)$ e triacilgliceróis $(r=0,04412 ; p=0,6777)$. 
Quanto ao grupo etário, observou-se que não houve diferença significativa em relação ao colesterol total $(p=0,3242)$, ao LDL-c $(p=0,3749)$, ao triacilglicerol $(p=0,0948)$ e ao HDL-c $(p=0,9149)$.

A TABELA 8 demonstra a análise descritiva dos perfis lipêmicos observados na população estudada, segundo o grupo etário.

TABELA 8 - Distribuição dos valores da média, desvios-padrão, mínimos e máximos de ríveis plasmáticos de lípides na população de estudo, segundo o grupo etário. InCor - HCFMUSP. 1997-2001.

\begin{tabular}{|c|c|c|c|c|c|c|c|}
\hline $\begin{array}{l}\text { Grupo } \\
\text { etário }\end{array}$ & Variável & $n$ & $\begin{array}{l}\text { Média } \\
\text { (mg/dL) }\end{array}$ & $\begin{array}{c}\mathrm{DP}^{*} \\
(\mathrm{mg} / \mathrm{dL})\end{array}$ & $\begin{array}{l}\text { Mínimo } \\
(\mathrm{mg} / \mathrm{dL})\end{array}$ & $\begin{array}{c}\text { Máximo } \\
(\mathrm{mg} / \mathrm{dL})\end{array}$ & $p$ \\
\hline $\begin{array}{c}45 \mid--55 \\
\text { anos }\end{array}$ & $\begin{array}{c}\text { Colesterol } \\
\text { HDL - c } \\
T^{\star * *} \\
L^{*} L^{-c}\end{array}$ & $\begin{array}{l}62 \\
62 \\
62 \\
62\end{array}$ & $\begin{array}{c}227,65 \\
43,05 \\
164,40 \\
152,27\end{array}$ & $\begin{array}{c}38,29 \\
9,03 \\
70,23 \\
44,01\end{array}$ & $\begin{array}{c}137,00 \\
25,00 \\
110,00 \\
70,00\end{array}$ & $\begin{array}{c}312,00 \\
72,00 \\
384,00 \\
391,00\end{array}$ & 0,324 \\
\hline $\begin{array}{c}55 \text { |-- } 65 \\
\text { anos }\end{array}$ & 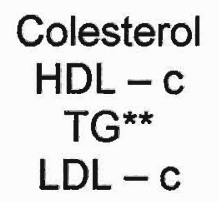 & $\begin{array}{l}76 \\
76 \\
76 \\
76\end{array}$ & $\begin{array}{c}234,47 \\
43,50 \\
171,14 \\
157,67\end{array}$ & $\begin{array}{l}46,18 \\
11,59 \\
88,85 \\
42,05\end{array}$ & $\begin{array}{c}132,00 \\
20,00 \\
56,00 \\
72,00\end{array}$ & $\begin{array}{c}373,00 \\
70,00 \\
691,00 \\
301,00\end{array}$ & 0,375 \\
\hline $\begin{array}{c}65 \text { |-- } 75 \\
\text { anos }\end{array}$ & $\begin{array}{c}\text { Colesterol } \\
\text { HDL - c } \\
T^{* *} \\
L^{*}-c\end{array}$ & $\begin{array}{l}64 \\
64 \\
64 \\
64\end{array}$ & $\begin{array}{c}241,53 \\
43,02 \\
189,27 \\
159,67\end{array}$ & $\begin{array}{l}44,24 \\
10,01 \\
89,12 \\
45,73\end{array}$ & $\begin{array}{c}137,00 \\
22,00 \\
59,00 \\
24,00\end{array}$ & $\begin{array}{c}380,00 \\
64,00 \\
479,00 \\
312,00\end{array}$ & 0,095 \\
\hline $\begin{array}{l}\geq 75 \\
\text { anos }\end{array}$ & $\begin{array}{c}\text { Colesterol } \\
\text { HDL }-\mathrm{C} \\
\mathrm{TG} \mathrm{G}^{\star *} \\
\mathrm{LDL}-\mathrm{c}\end{array}$ & $\begin{array}{l}15 \\
15 \\
15 \\
15\end{array}$ & $\begin{array}{c}229,00 \\
47,87 \\
137,73 \\
153,53 \\
\end{array}$ & $\begin{array}{c}41,78 \\
8,75 \\
45,23 \\
40,07\end{array}$ & $\begin{array}{c}161,00 \\
31,00 \\
56,00 \\
87,00 \\
\end{array}$ & $\begin{array}{c}302,00 \\
60,00 \\
215,00 \\
224,00 \\
\end{array}$ & 0,915 \\
\hline
\end{tabular}

*DP: Desvios-padrão; **TG: Triacilgliceróis 
Foi também observado, que não houve correlação entre os grupos etários, o IMC e os níveis plasmáticos de lípides, exceto o grupo etário entre 65 e 75 anos, no qual foi possível observar correlação positiva e significativa $(r=0,42987 ; p=0,0004)$ entre 0 IMC e os níveis plasmáticos de triacilgliceróis. As correlações encontram-se nas FIGURAS 12 a 27.

FIGURA 12 - Correlação entre o IMC e os níveis plasmáticos de colesterol, no grupo etário entre 45 e 55 anos. InCor - HCFMUSP. 1997-2001.

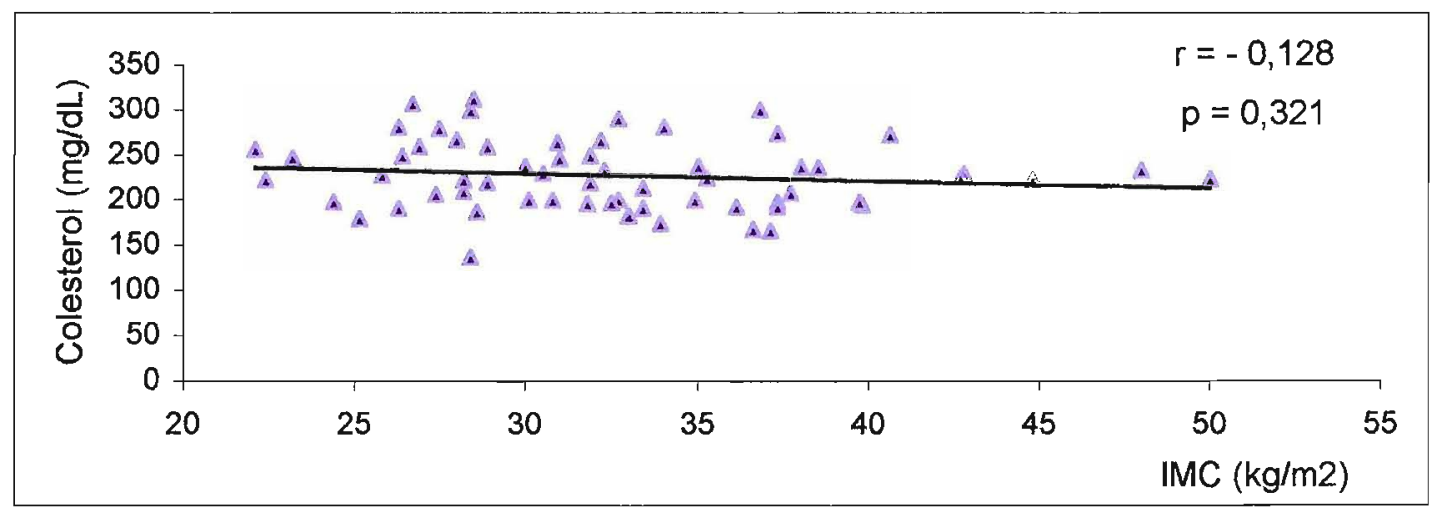

FIGURA 13 - Correlação entre o IMC e os níveis plasmáticos de LDL-C, no grupo etário entre 45 e 55 anos. InCor - HCFMUSP. 1997-2001.

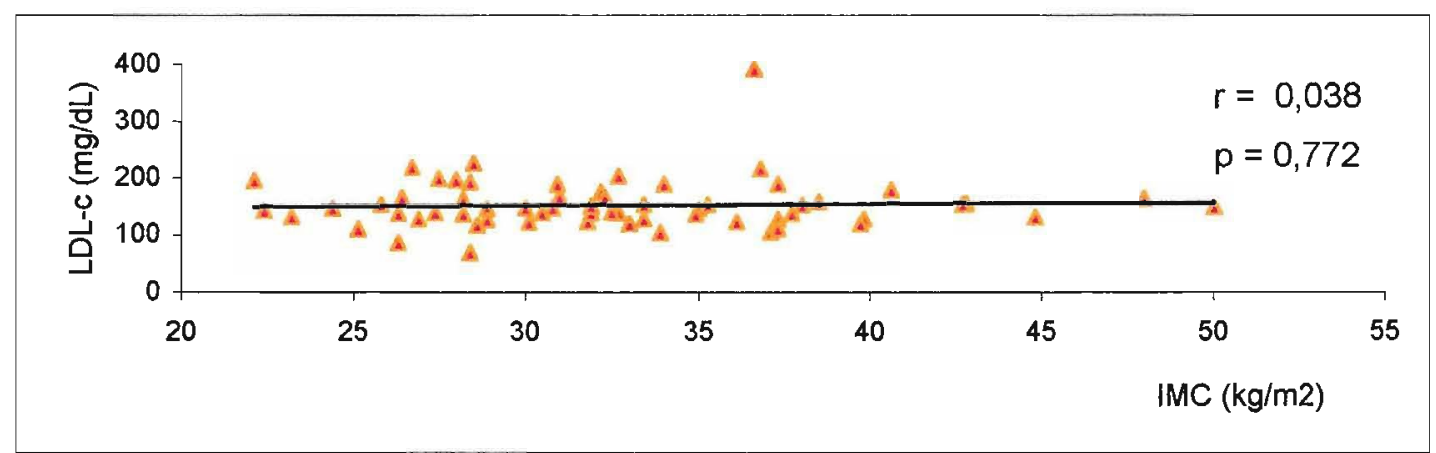


FIGURA 14 - Correlação entre o IMC e os níveis plasmáticos de HDL-c, no grupo etário entre 45 e 55 anos. InCor - HCFMUSP. 1997-2001.

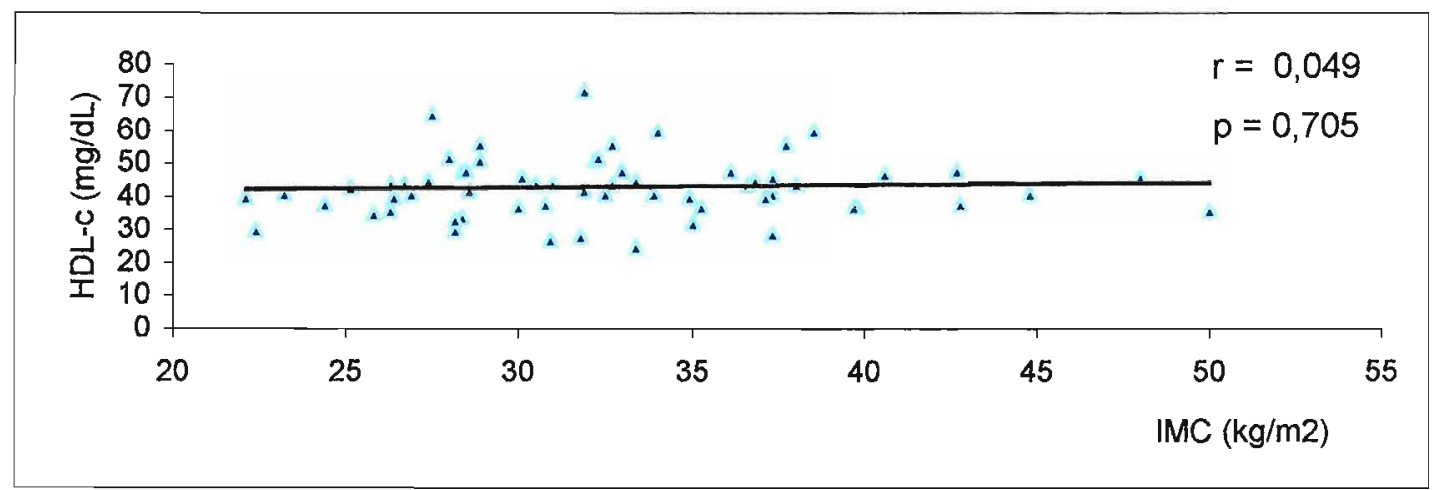

FIGURA 15 - Correlação entre 0 IMC e os níveis plasmáticos de triacilgliceróis, no grupo etário entre 45 e 55 anos. InCor - HCFMUSP. 19972001.

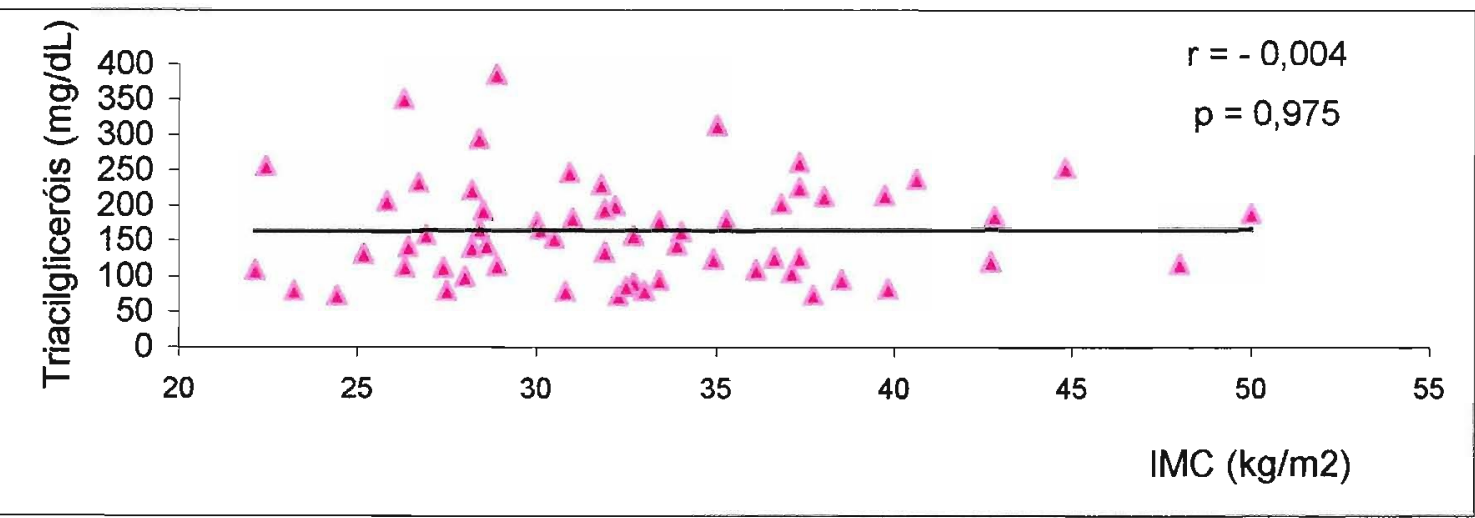


FIGURA 16 - Correlação entre o IMC e os níveis plasmáticos de colesterol, no grupo etário entre 55 e 65 anos. InCor - HCFMUSP. 1997-2001.

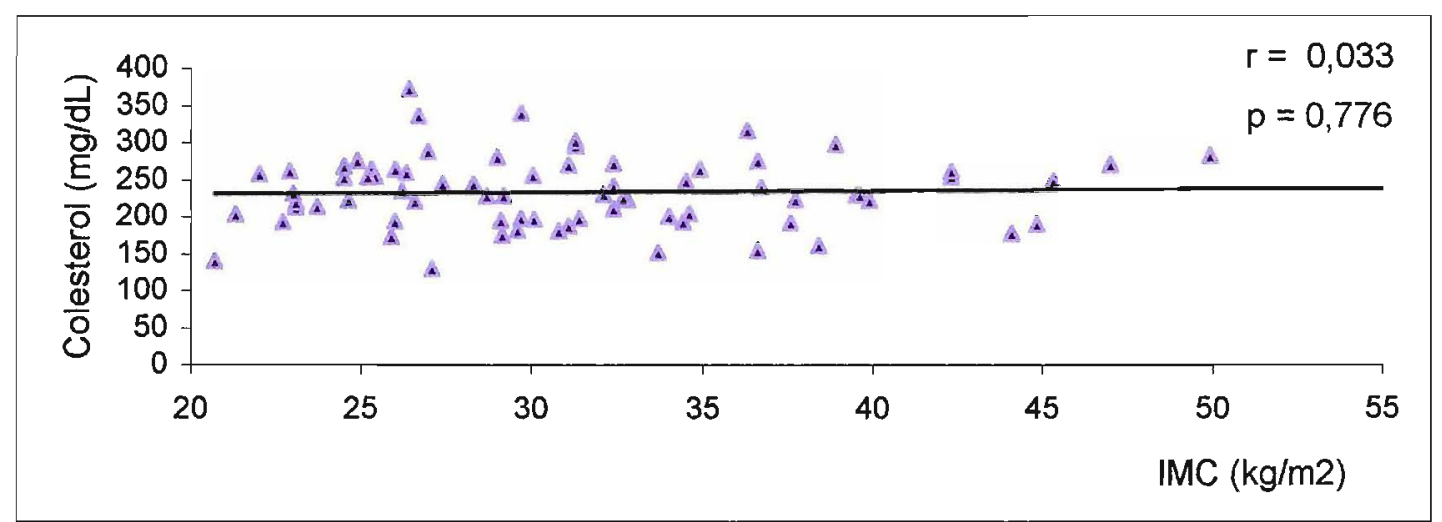

FIGURA 17 - Correlação entre o IMC e os níveis plasmáticos de LDL-C, no grupo etário entre 55 e 65 anos. InCor - HCFMUSP. 1997-2001.

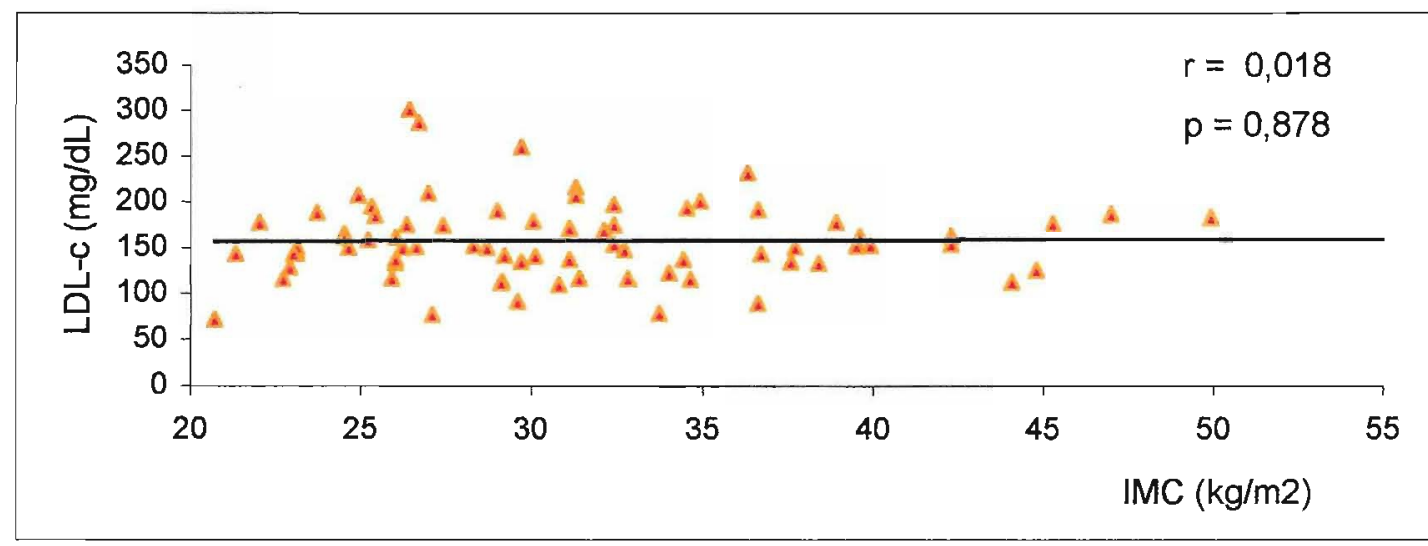


FIGURA 18 - Correlação entre o IMC e os níveis plasmáticos de HDL-c, no grupo etário entre 55 e 65 anos. InCor - HCFMUSP. 1997-2001.

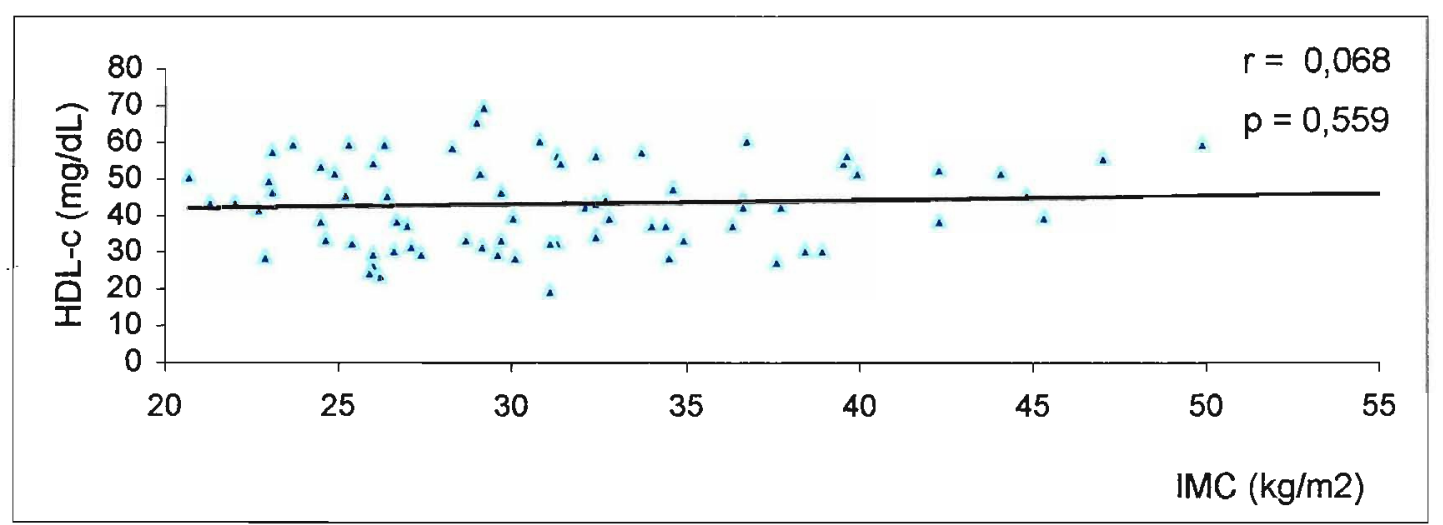

FIGURA 19 - Correlação entre o IMC e os níveis plasmáticos de triacilgliceróis, no grupo etário entre 55 e 65 anos. InCor - HCFMUSP. 19972001.

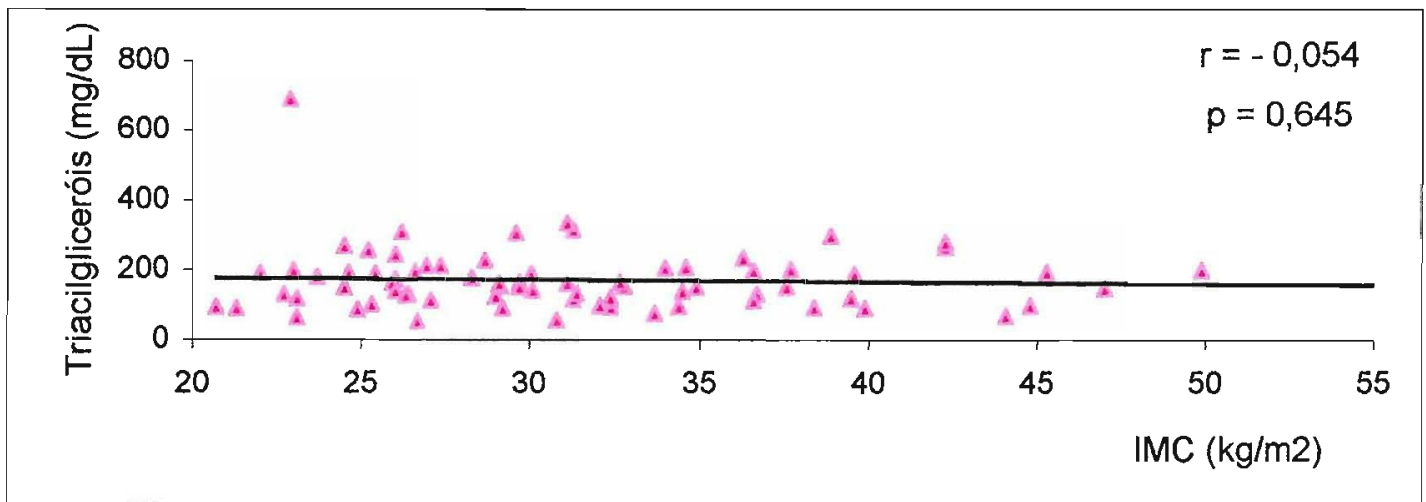


FIGURA 20 - Correlação entre o IMC e os niveis plasmáticos de colesterol, no grupo etário entre 65 e 75 anos. InCor - HCFMUSP. 1997-2001.

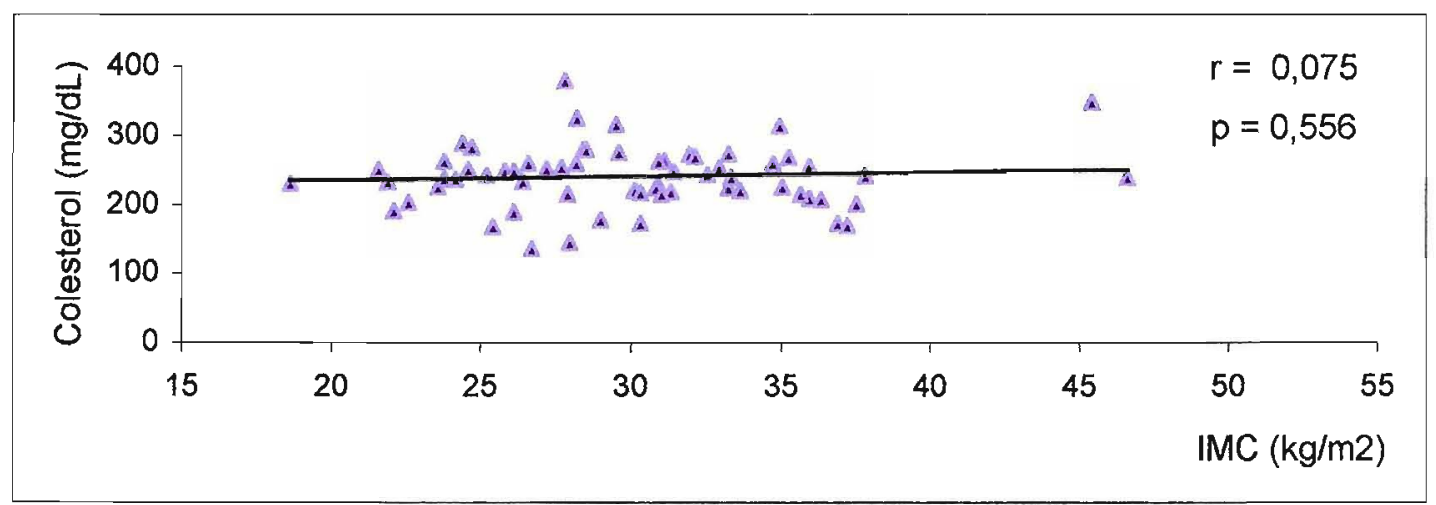

FIGURA 21 - Correlação entre o IMC e os níveis plasmáticos de LDL-c, no grupo etário entre 65 e 75 anos. InCor - HCFMUSP. 1997-2001.

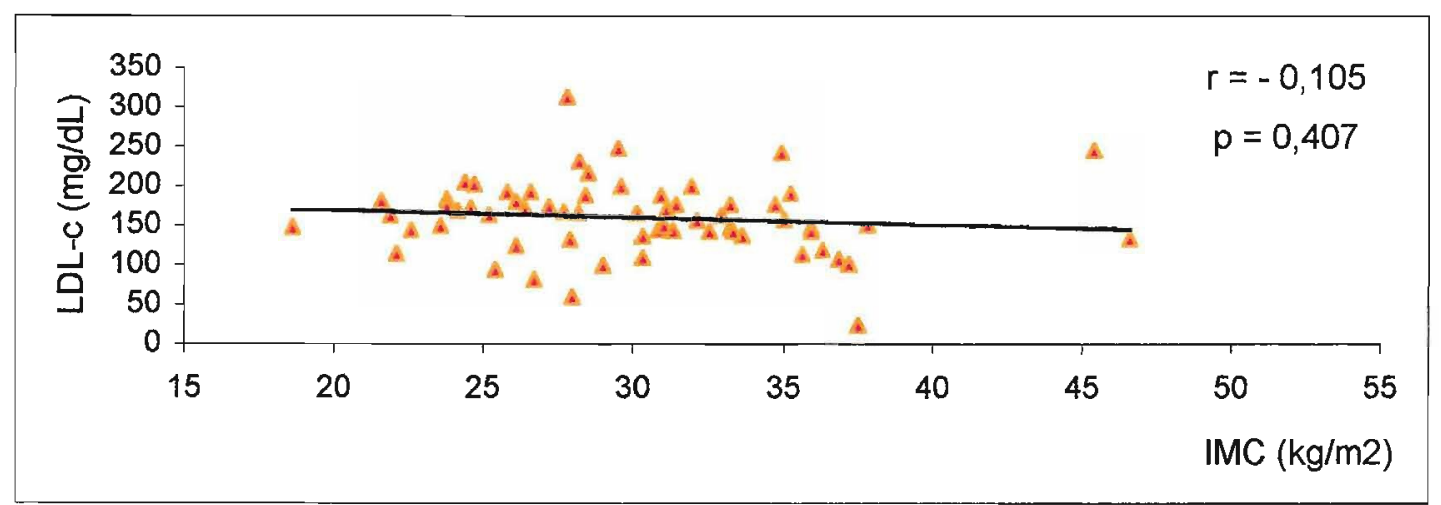


FIGURA 22 - Correlação entre o IMC e os níveis plasmáticos de HDL-c, no grupo etário entre 65 e 75 anos. InCor - HCFMUSP. 1997-2001.

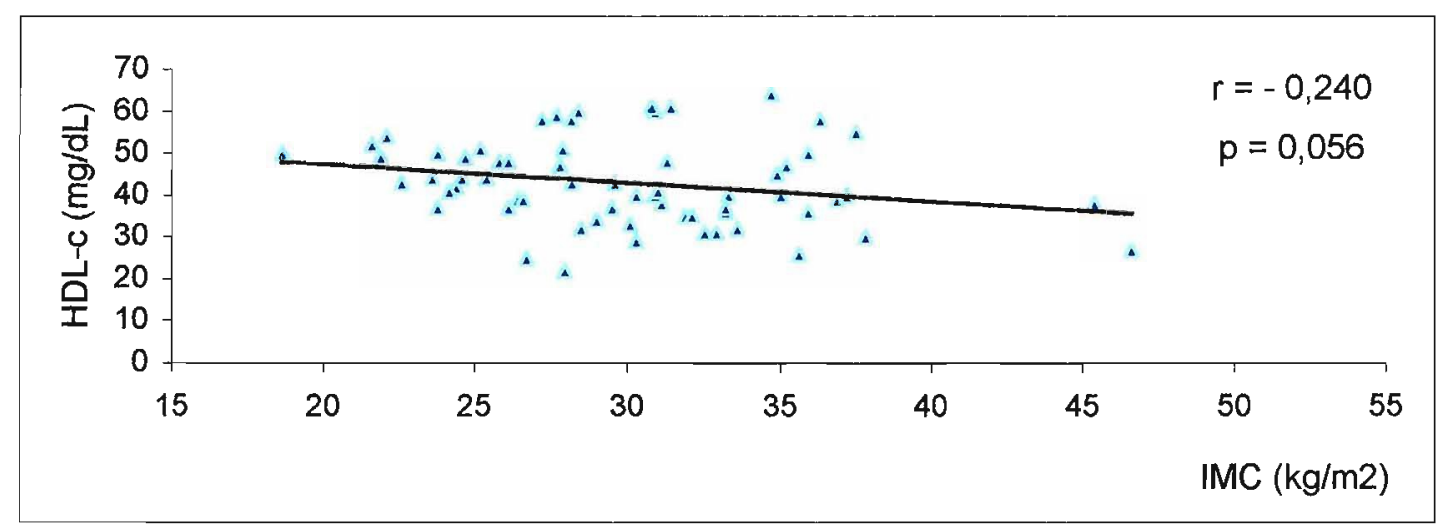

FIGURA 23 - Correlação entre o IMC e os níveis plasmáticos de triacilgliceróis, no grupo etário entre 65 e 75 anos. InCor - HCFMUSP. 19972001.

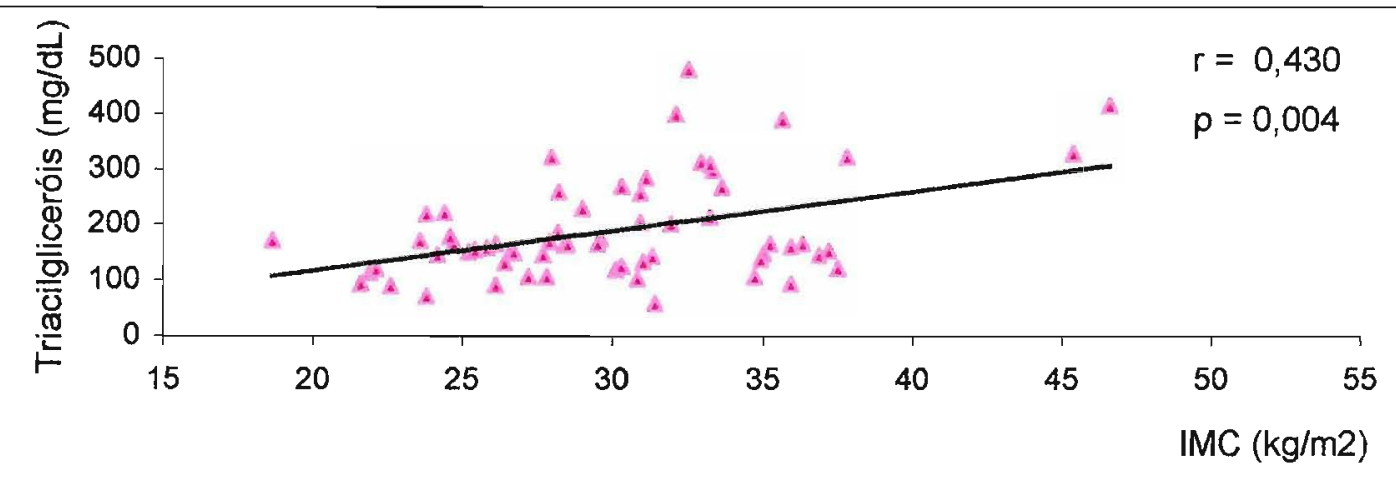


FIGURA 24 - Correlação entre o IMC e os níveis plasmáticos de colesterol, no grupo etário $\geq 75$ anos. InCor - HCFMUSP. 1997-2001.

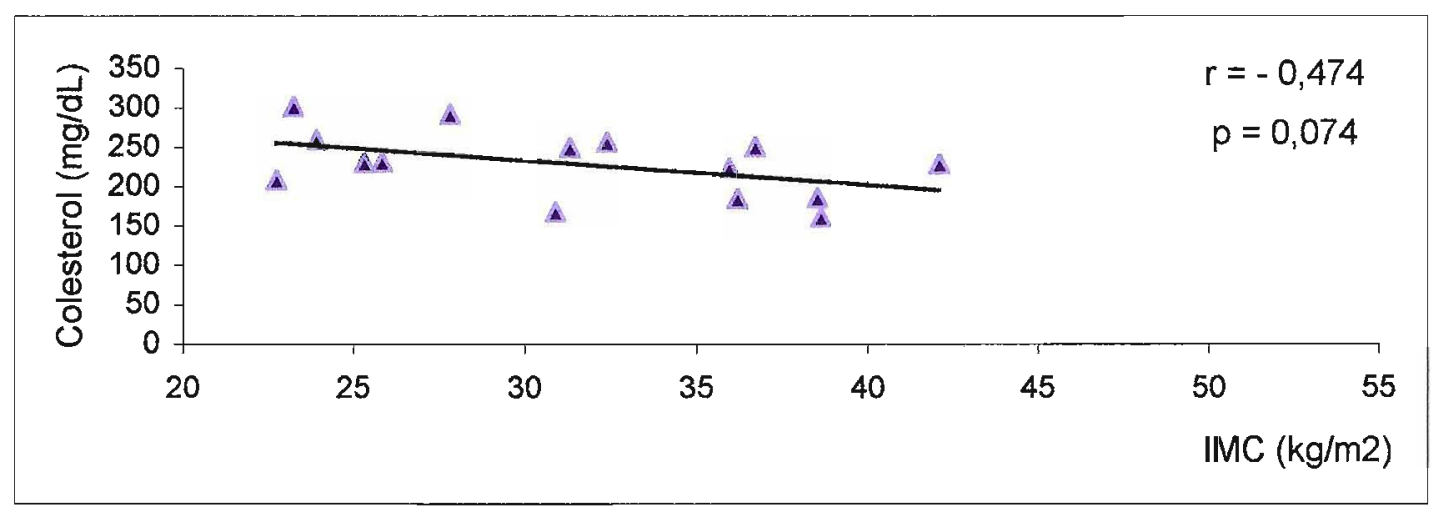

FIGURA 25 - Correlação entre o IIMC e os níveis plasmáticos de LDL-c, no grupo etário $\geq 75$ anos. InCor - HCFMUSP. 1997-2001.

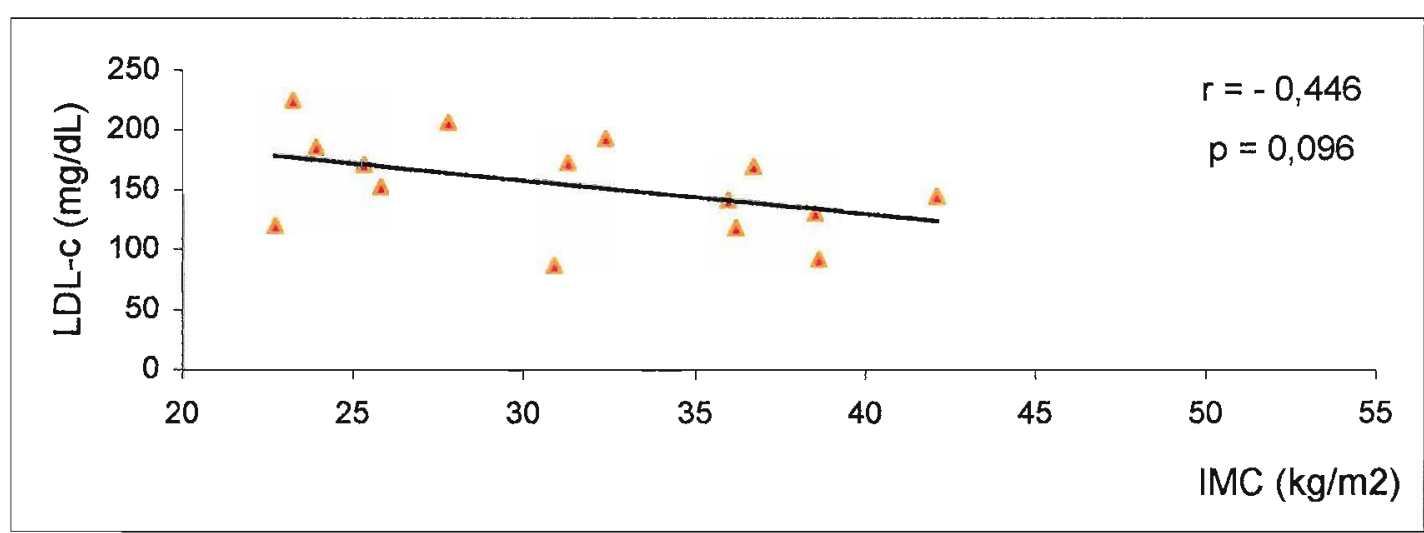


FIGURA 26 - Correlação entre o IMC e os níveis plasmáticos de HDL-C, no grupo etário $\geq 75$ anos. InCor - HCFMUSP. 1997-2001.

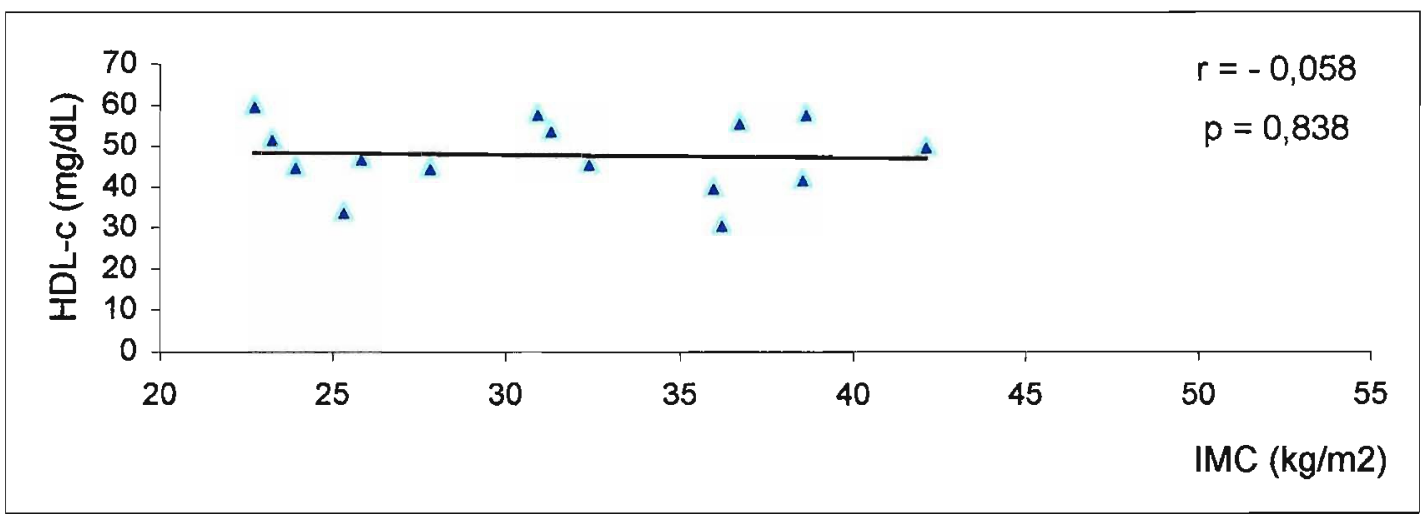

FIGURA 27 - Correlação entre o IMC e os níveis plasmáticos de triacilgliceróis, no grupo etário $\geq 75$ anos. InCor - HCFMUSP. 1997-2001.

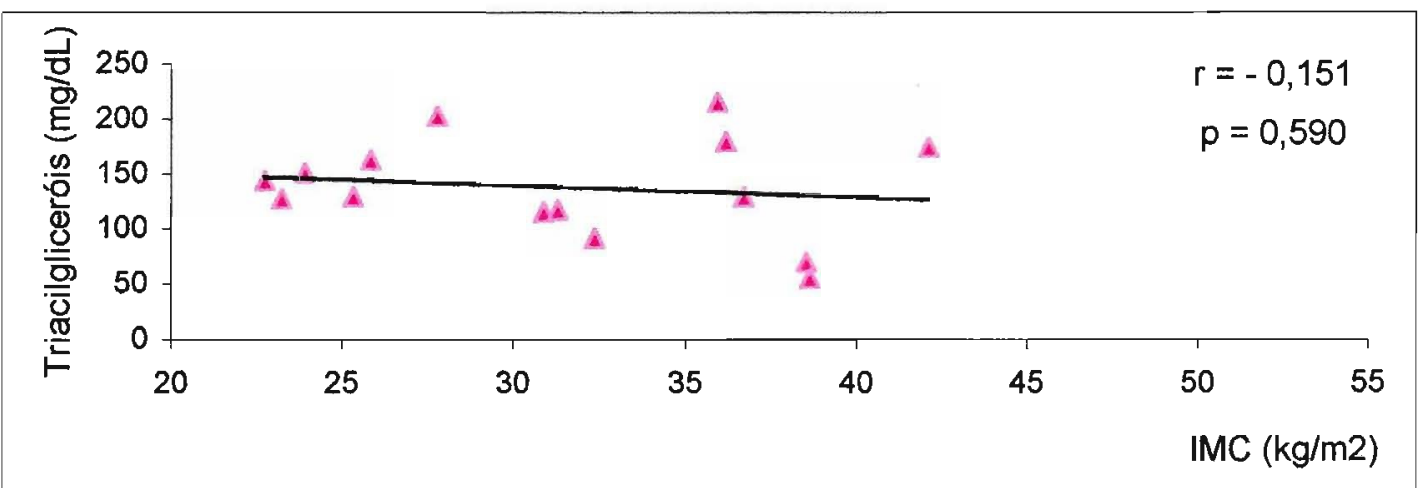




\subsection{Consumo alimentar}

Em relação ao consumo alimentar, observou-se que na distribuição percentual dos macronutrientes, $59 \%$ da população de estudo referiram consumo de gorduras acima do limite superior aceitável e $42 \%$ da população referiram consumo de carboidratos menor do que o limite inferior aceitável para este nutriente. Os demais resultados encontram-se na FIGURA 28.

FIGURA 28 - Distribuição da população de estudo, segundo a distribuição percentual do consumo de macronutrientes. InCor-HCFMUSP. 1997-2001.

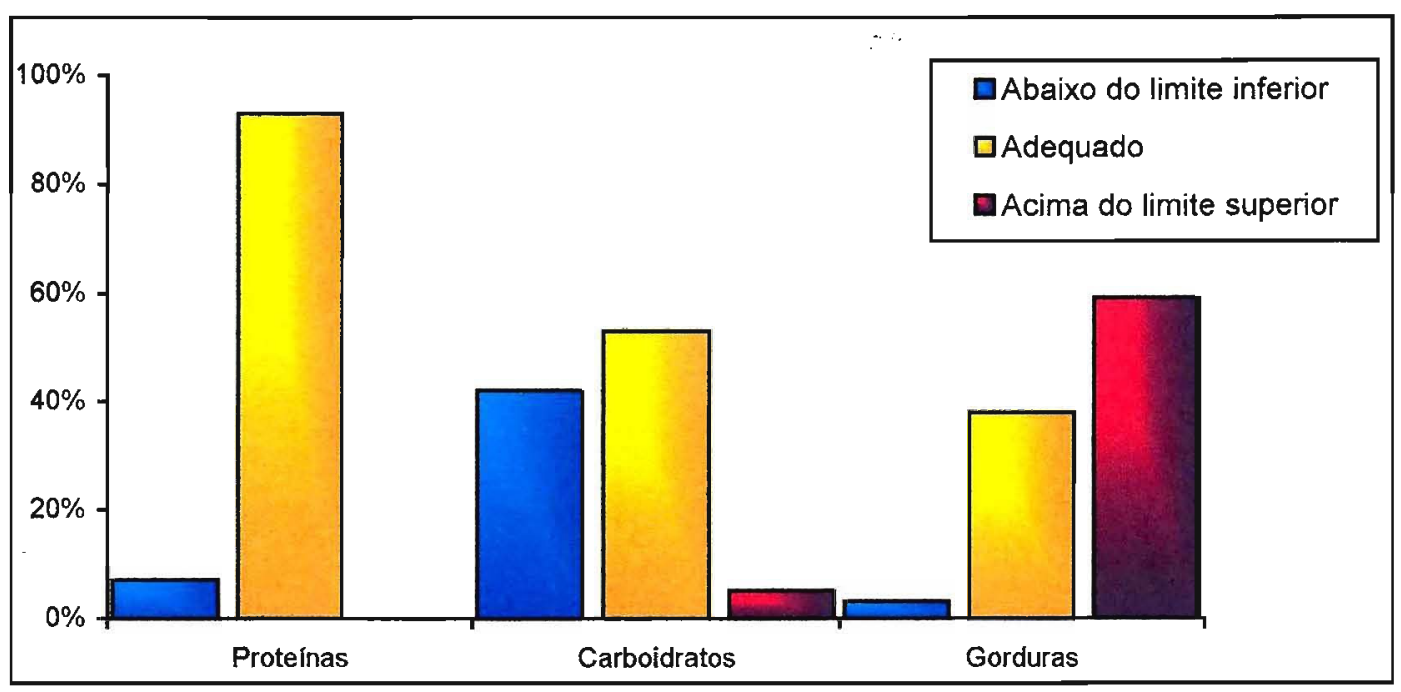

Quanto às fibras alimentares, observou-se que $95 \%$ da população estudada referiram consumo deficiente.

A TABELA 9 demonstra a análise descritiva de calorias e fibras alimentares da população estudada. 
TABELA 9 - Valores da média, desvios-padrão, mediana, mínimos e máximos de calorias e fibras alimentares da população de estudo. InCor HCFMUSP. 1997-2001.

\begin{tabular}{lccccc}
\hline Variável & Média & $\mathrm{DP}^{*}$ & Mediana & Mínimo & Máximo \\
\hline Calorias (kcal) & 1564,00 & 617,83 & 1496,00 & 432,86 & 4924,00 \\
Fibras alimentares (g) & 7,28 & 5,74 & 5,78 & 0,26 & 34,73 \\
\hline
\end{tabular}

*DP: Desvios-padrão

Quanto à idade houve diferença significativa em relação ao consumo de proteínas $(p=0,0044)$ e gorduras $(p=0,0304)$, pois foi possível observar, por meio do teste de Bonferroni, que os grupos de 55-65 anos e 65-75 anos diferem entre si $(p<0,05)$, sendo que o primeiro apresenta consumo significativamente maior que o segundo.

Por meio do teste não paramétrico de Kruskal-Wallis, observou-se que os grupos etários diferem, entre si, em relação ao consumo de fibras alimentares $(p=0,0062)$ e, por meio do teste de Dunn, foi possível observar que o grupo etário de 45 a 55 difere significativamente do grupo de 65 a 75 anos $(p<0,05)$, ou seja, o grupo mais idoso consome mais fibras alimentares que o grupo mais jovem.

A TABELA 10 demonstra a análise descritiva de calorias, macronutrientes e fibras alimentares observados na população estudada, segundo o grupo etário. 
TABELA 10 - Valores da média, desvios-padrão, mínimos e máximos de calorias, macronutrientes e fibras alimentares da população de estudo, segundo o grupo etário. InCor - HCFMUSP. 1997-2001.

\begin{tabular}{|c|c|c|c|c|c|c|}
\hline $\begin{array}{l}\text { Grupo } \\
\text { etário }\end{array}$ & Variável & $\mathrm{n}$ & Média & $\mathrm{DP}^{\star}$ & Mínimo & Máximo \\
\hline $45 \mid--55$ & Calorias (kcal) & 62 & 1597,80 & 700,00 & 707,33 & 4923,79 \\
\hline \multirow[t]{4}{*}{ anos } & Proteínas (g) & 62 & 59,83 & 30,17 & 5,75 & 177,65 \\
\hline & Gorduras (g) & 62 & 69,10 & 33,73 & 12,48 & 219,55 \\
\hline & Carboidratos (g) & 62 & 185,46 & 112,12 & 28,53 & 662,41 \\
\hline & Fibras alimentares $(\mathrm{g})$ & 62 & 6,22 & 5,89 & 0,44 & 28 \\
\hline $55 \mid--65$ & Calorias (kcal) & 76 & 1689,90 & 619,98 & 746,11 & 4165,67 \\
\hline \multirow[t]{4}{*}{ anos } & Proteínas (g) & 76 & 71,25 & 31,14 & 14,50 & 175,00 \\
\hline & Gorduras (g) & 76 & 74,86 & 38,76 & 14,84 & 231,30 \\
\hline & Carboidratos (g) & 76 & 182,62 & 80,42 & 58,22 & 481,76 \\
\hline & Fibras alimentares (g) & 76 & 7,07 & 5,48 & 0,81 & 28,39 \\
\hline $65 \mid---75$ & Calorias (kcal) & 64 & 1415,14 & 548,12 & 432,86 & 2810,87 \\
\hline \multirow[t]{4}{*}{ anos } & Proteínas (g) & 64 & 54,89 & 24,25 & 7,45 & 113,60 \\
\hline & Gorduras (g) & 64 & 58,39 & 27,87 & 14,51 & 180,08 \\
\hline & Carboidratos (g) & 64 & 167,68 & 85,77 & 16,46 & 479,69 \\
\hline & Fibras alimentares (g) & 64 & 8,83 & 6,06 & 0,26 & 34,73 \\
\hline$\geq 75$ & Calorias (kcal) & 15 & 1425,21 & 360,78 & 772,07 & 2143,29 \\
\hline \multirow[t]{4}{*}{ anos } & Proteínas (g) & 15 & 54,95 & 17,93 & 23,68 & 80,55 \\
\hline & Gorduras (g) & 15 & 60,59 & 27,35 & 14,39 & 116,17 \\
\hline & Carboidratos (g) & 15 & 165,22 & 50,36 & 61,59 & 233,93 \\
\hline & Fibras alimentares (g) & 15 & 6,10 & 3,76 & 1,51 & 14,04 \\
\hline
\end{tabular}

${ }^{*}$ DP: Desvios-padrão

Em relação à idade, não se observou correlação significativa entre o consumo de proteínas $(r=-0,1203 ; p=0,0769)$, de carboidratos $(r=-0,1277$; 
$p=0,0603)$ e de fibras alimentares $(r=0,08207 ; p=0,2286)$, porém observouse correlação negativa e significativa entre o total de calorias $(r=-0,1800$ e $p=0,008)$ e gorduras $(r=-0,1719 ; p=0,011)$, demonstrando que quanto maior a idade, menor o total calórico e de gorduras na população de estudo, conforme as FIGURAS 29 e 30 , respectivamente.

FIGURA 29 - Correlação entre a idade e o total calórico da dieta na população de estudo. InCor - HCFMUSP. 1997-2001.

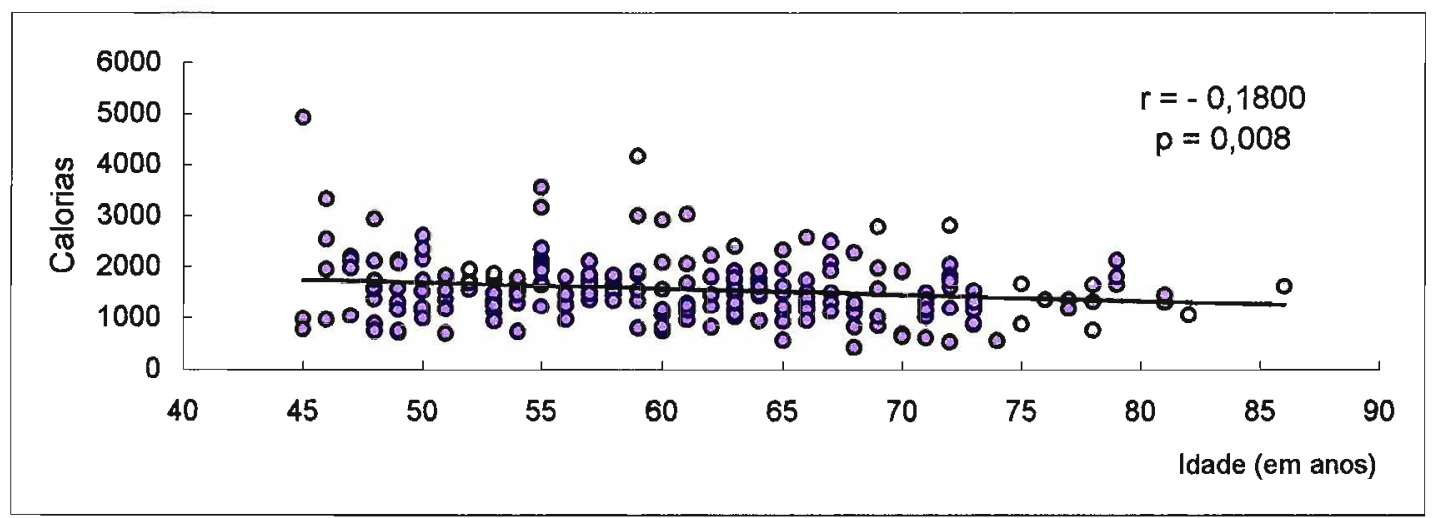

FIGURA 30 - Correlação entre a idade e o total de gorduras da dieta na população de estudo, segundo Pearson. InCor - HCFMUSP. 1997-2001.

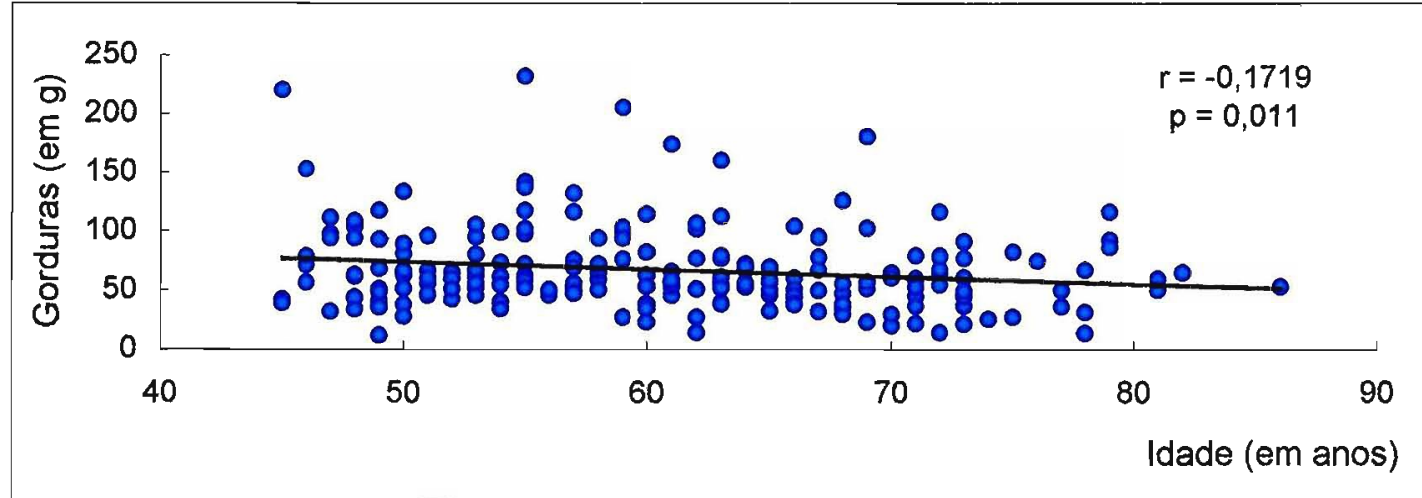




\section{DIscussão}

A média de idade observada evidencia que, a partir da quinta década de vida, a doença cardiovascular pode ser um importante determinante de morbidade na população feminina (GORODESKI 2002), uma vez que o aumento da idade está associado com a obesidade, dislipidemias, intolerância à glicose e hipertensão (KO, CHAN, WOO, LAU, YEUNG, CHOW et al. 1997).

Em relação aos homens, as mulheres apresentam pior prognóstico e morrem mais freqüentemente após o seu primeiro evento cardíaco (WELTY 2001).

A DAC manifesta-se, em média, 10 anos mais tarde do que nos homens, devido ao efeito protetor dos estrógenos e o pior prognóstico se deve somente ao fato de as mulheres apresentarem mais fatores de risco ao infartar ou se de fato há um fator biológico distinto que as coloca num patamar de risco superior ainda requer mais estudos elucidativos (LIMA \& NUSSBACHER 1996).

Tem-se observado que complicações após o procedimento de revascularização, tanto angioplastia como cirurgia de revascularização do miocárdio, são mais comuns nas mulheres devido a menor superfície corpórea, a menor resposta à ação da aspirina (o que favorece a agregação 
plaquetária) e, possivelmente, a fatores biológicos (LIMA \& NUSSBACHER 1996).

CARAMELLI (1997), em estudo no qual observou as tendências seculares da população com doença isquêmica do coração em hospital especializado, verificou aumento significativo da idade e da freqüência do sexo feminino nos pacientes com as formas aguda e crônica da doença isquêmica do coração e ainda, a maior prevalência de pacientes do sexo feminino com idade avançada em relação ao sexo masculino.

A presença de mulheres mais jovens na população de estudo é preocupante, pois com o aumento da expectativa de vida, um número maior de mulheres poderá viver de 30 a 40 anos em condições de significativa redução hormonal, o que pode proporcionar aumento na prevalência de inúmeras doenças crônicas (JACOBSEN et al. 1999; FAVARATO 2000; CUTSON \& MEULEMAN 2000).

A partir da análise dos dados antropométricos da população de estudo, foi possível observar que estes seguem a tendência mundial relacionada à alta prevalência de pré-obesidade e obesidade, que aumenta tanto em países desenvolvidos como naqueles em desenvolvimento, independentemente do poder socioeconômico (STAMLER 1993; MONDINI \& MONTEIRO 1994; MONTEIRO et al. 2001). 
O valor médio de IMC encontrado neste grupo de pacientes $\left(31,37 \pm 6,34 \mathrm{~kg} / \mathrm{m}^{2}\right)$ foi superior ao encontrado em estudo anterior, que avaliou mulheres no climatério assistidas pelo Ambulatório de Saúde da Mulher Climatérica do Centro de Saúde-Escola "Geraldo de Paula Souza" da Faculdade de Saúde Pública da Universidade de São Paulo, que foi de $29,3 \pm 6,2 \mathrm{~kg} / \mathrm{m}^{2}$ (MONTILLA 2001).

As mulheres mais jovens apresentam maior ganho de peso (DUBNOV et al. 2003) e no presente estudo, o grupo etário de 45 a 55 anos foi o que apresentou maior média de peso $(78,12 \pm 15,60 \mathrm{~kg})$.

No climatério, é comum a observação de ganho de peso, devido às profundas mudanças físicas e emocionais a que as mulheres, nesta fase da vida, estão submetidas e os resultados se estendem após a menopausa, o que pode, talvez, explicar o maior aumento de peso na faixa etária mais jovem (MONTILLA 2001; FAVARATO 2000).

Ao observar a classificação da população, quanto ao IMC, foi possivel perceber que $76 \%$ apresentavam excesso de peso, o que é preocupante, uma vez que a obesidade aumenta o risco para complicações da DAC e outras doenças e pode diminuir a qualidade de vida desta população (HILL 2000). 
Embora não tenha sido objetivo deste estudo, de modo geral, as mulheres na pré-menopausa, têm a gordura com distribuição mais periférica, uma vez que os estrógenos têm efeito sobre o depósito de gordura, particularmente acentuado, nas nádegas e coxas, e na pós-menopausa ocorre uma "redistribuição" desses depósitos, predominantemente na região abdominal (GUYTON 1993; LENIEUX et al. 1996). O acúmulo de gordura abdominal é um importante preditor de risco de DAC, pois está associado à intolerância à glicose e aos níveis de lípides plasmáticos elevados (AZEVEDO \& SEKEFF 1994).

Porém, apesar dos resultados deste estudo confirmarem a associação da menopausa com aumento do peso corporal, observou-se, também, um declínio de peso com o aumento da idade.

Tal fato pode estar refletindo a maior preocupação do sexo feminino com a estética corporal (ELL et al. 1999), ou pode ser ainda devido ao processo de envelhecimento.

Pacientes idosos tendem a apresentar alterações orgânicas e fisiológicas, como a perda de dentes, redução na sensibilidade gustativa, e, ainda, consumo inadequado de alimentos, bem como, 0 uso de medicamentos, que podem interferir não só no consumo de alimentos, mas também na absorção, metabolismo e excreção de nutrientes (MARUCCI \& 
GOMES 1997; ROLLS 1999; MacINTOSH et al. 2000; OMRAN \& MORLEY 2000; OLIVEIRA et al. 2003).

É importante ressaltar que as drogas que atuam no sistema cardiovascular são, normalmente, administradas por via oral o que acarreta alterações no paladar, diminuindo o consumo alimentar o que pode levar à perda de peso (MARUCCI \& GOMES 1997; OLIVEIRA et al. 2003).

A incidência de DAC em mulheres está relacionada à glicemia alterada. A população diabética apresenta prevalência aumentada de DAC, em relação à não diabética e, portanto, indivíduos diabéticos são considerados potenciais portadores de aterosclerose (MS 1993; AZEVEDO \& SEKEFF 1994; CASTELLI 1994; NÓBREGA 1998; SBC 2001).

A prevalência de diabetes melito do tipo 2 e de intolerância à glicose aumenta após os 40 anos, uma vez que a deficiência estrogênica é responsável pela piora da homeostase da glicose em mulheres, que são geneticamente susceptíveis, na pós-menopausa (WU et al. 2001).

No presente estudo, ao contrário dos achados na literatura, a prevalência de diabetes melito foi baixa. Observou-se que o grupo etário mais jovem foi aquele que apresentou maior prevalência de diabetes melito isolada. Isto talvez possa ser explicado pela maior média de peso observada 
nesta população e que, portanto, apresenta maior risco de manifestar a doença.

Ao associar a presença simultânea de diabetes melito e hipertensão arterial sistêmica, foi possível observar a alta prevalência desta condição clínica na população estudada.

A hipertensão arterial sistêmica é mais prevalente nas mulheres, principalmente após a menopausa, devido à diminuição estrogênica (LEGATO 1998; WENGER 1995), o que foi claramente observado no presente estudo, onde cerca de $80 \%$ apresentaram níveis pressóricos elevados.

Embora não tenha sido observada diferença significativa entre a presença de hipertensão arterial sistêmica e estado nutricional, foi possível observar que a maior prevalência de hipertensão foi entre aquelas pacientes com o valor mais elevado de IMC.

Tais resultados vieram ao encontro daqueles observados em um estudo transversal, cujo objetivo foi identificar a relação entre hormônios sexuais femininos e níveis pressóricos em mulheres na pós-menopausa, onde foi possível observar correlação positiva entre a pressão arterial e o IMC (SHELLEY et al. 1998). 
Os estrógenos agem de forma similar aos agentes bloqueadores dos canais de cálcio e no sistema renina-angiotensina, cuja ausência favorece o aumento dos níveis pressóricos (BONDUKI et al. 2001), em acréscimo, o período que precede a menopausa é caracterizado por importantes mudanças do estilo de vida, (como a falta de atividade física), as quais podem aumentar o risco de elevação da pressão arterial (AMIGONI et al. 1999).

As mulheres na pós-menopausa, além da tendência ao ganho de peso, conforme discutido anteriormente, também estão susceptíveis a apresentarem alterações no metabolismo lipêmico devido à privação estrogênica que eleva os niveis de colesterol total, lipoproteínas e triacilgliceróis acarretando, a esta população, um perfil lipêmico altamente favorável à aterogênese, principalmente quando associada à diabetes melito e hipertensão (PASQUALI et al. 1997; O'BRIEN \& NGUYEN 1997), conforme observado no estudo.

Em um estudo de amostras populacionais de nove capitais brasileiras - Manaus, Fortaleza, Salvador, Distrito Federal, Goiânia, Belo Horizonte, São Paulo, Curitiba e Porto Alegre - a fim de traçar o perfil lipêmico da população brasileira, observou-se variação significativa quanto ao gênero e idade, uma vez que, as mulheres apresentaram médias de valores de colesterol total mais altas do que os homens $(183,0 \mathrm{mg} / \mathrm{dL} \times 178,1 \mathrm{mg} / \mathrm{dL} ; \mathrm{p}=$ 0,0035), com progressivo aumento com a idade, principalmente após os 49 
anos $(206,2 \mathrm{mg} / \mathrm{dL} \times 190 \mathrm{mg} / \mathrm{dL} ; \mathrm{p}=0,0002)$, em comparação aos homens (GUIMARÃES et al. 1998).

Por sua vez, os níveis de LDL-c e triacilgliceróis aumentam com a idade principalmente no sexo feminino (LUZ et al. 1990; BERTOLAMI et al. 1993; MARTINS et al. 1996).

Embora, neste estudo, não tenha sido observada correlação entre os níveis lipêmicos e a idade, tais resultados foram ao encontro daqueles observados em estudos onde se compararam mulheres na pré e pósmenopausa (STEVENSON et al. 1993; YAMAMOTO et al. 1998; ALOYSIO et al. 1999), sendo que a elevação dos níveis lipêmicos, nestas últimas, independe da idade, ou seja, a menopausa, por si só, parece resultar no aumento do colesterol total e LDL-c, conforme também observado no presente estudo.

Não foi possível observar, na população estudada, correlação entre as categorias de estado nutricional, segundo o IMC, em relação aos níveis lipêmicos.

A ocorrência de tal observação, provavelmente pode ser explicada pela maior prevalência de uso de medicamentos hipolipemiantes, o que pode ter favorecido melhor perfil lipêmico, mesmo nas mulheres mais obesas, bem como, a fatores relacionados à variação analítica, tais como, a 
variabilidade biológica, duração do jejum e postura durante a coleta, entre outros (SBC 2001).

Evidências demonstram que a terapêutica de reposição hormonal após a menopausa tem um efeito benéfico sobre o metabolismo lipídico, ósseo, sistema vascular e sistemas de coagulação e fibrinólise (GEBARA 1996). No entanto, alguns efeitos indesejáveis, tais como sangramento genital e risco de câncer do endométrio e mama, porém a grande diminuição da mortalidade por causas cardiovasculares decorrente da reposição estrogênica pode compensar estes riscos (MELO et al. 1996).

Apesar de não ter sido objeto de estudo, observou-se poucas menções do uso de terapia de reposição hormonal, talvez pela sua não utilização ou pelo não questionamento por parte do cardiologista. A utilização de terapia de reposição hormonal talvez poderia explicar o perfil lipêmico favorável na população estudada.

Em 1994, MONDINI \& MONTEIRO, ao estudarem as modificações no padrão da alimentação urbana brasileira, constataram tendência de menor contribuição dos carboidratos no consumo calórico total e sua substituição por gorduras.

Em 1999, FONSECA et al. avaliaram os hábitos alimentares de funcionários de um banco estatal e observaram que as escolhas alimentares 
estavam relacionadas àqueles alimentos com alto teor de gordura, açúcar e sal, principalmente entre os funcionários mais jovens.

Quanto à idade, em estudo que associou a dieta com o início da menopausa na população feminina japonesa, foi possível observar aumento constante no consumo de gorduras, conforme a idade de início da menopausa (NAGATA et al. 1998).

Os resultados do presente estudo vêm ao encontro daqueles citados anteriormente, nos quais também se observou maior média de consumo de gorduras.

Os componentes dietéticos que exercem maior influência no risco para DAC são a ingestão de gordura total, o tipo de ácidos graxos da dieta, sendo que os saturados apresentam maior poder deletério, o colesterol e a fonte de proteínas (FONSECA et al. 1999).

O "Estudo dos Sete Países" (KEYS 1986), que durante 15 anos avaliou 11.579 homens com idade entre 40 e 59 anos, foi o pioneiro a afirmar que os países com maior consumo de gordura (superior a $35 \%$ das calorias diárias) apresentaram maior mortalidade por DAC. 
Outros estudos, experimentais e observacionais, apresentaram resultados semelhantes (PIETINEN et al. 1996; TRICHPOULOU \& LAGIOU 1997; CUNNINGHAM 1998).

Devido à não disponibilidade de dados referentes ao teor de gordura saturada, monoinsaturada e polinsaturada dos alimentos, no programa de computador utilizado no cálculo, não foi possível verificar o consumo destes nutrientes o que poderia caracterizar mais adequadamente a população de estudo.

Os óleos vegetais são boas fontes de ácidos graxos polinsaturados (SIZER \& WHITNEY 2003) e desempenham efeito hemodinâmico protetor, quando consumidos em pequenas quantidades (SIMOPOULOS 1999).

Em estudo realizado por HU et al. (1997) foi observado associação inversa entre o consumo de gordura polinsaturada e a incidência de DAC.

Em estudo realizado por POSNER et al. (1993), foi possivel observar que o consumo de gordura polinsaturada, por mulheres na pós-menopausa, reduziu os níveis plasmáticos de colesterol o que pode levar à diminuição do risco para DAC nesta população.

Vários estudos, dentre eles o de McCRORY et al. (1999) e HILL et al. (2000), mostraram a relação entre excesso de gordura dietética e obesidade. 
As causas dessa relação são que, além das dietas ricas em gorduras serem palatáveis, possuem alta densidade energética e são facilmente armazenadas quando em excesso (HILL et al. 2000).

A diminuição do consumo de gorduras, dentre outros fatores, pode resultar na perda de peso.

LICHTENSTEIN \& VAN HORN (1998) observaram que programas de aconselhamento nutricional podem ter resultados satisfatórios, quando bem conduzidos, como por exemplo, o "Lifestyle Heart Trial" no qual observou-se, após uma diminuição do consumo de gorduras de $32 \%$ para $7 \%$ das calorias totais, redução no peso de $11 \mathrm{~kg}$ após o primeiro ano de intervenção. Tais observações sugerem que a redução do consumo de gorduras, principalmente quando associada a outras atividades, como acompanhamento psicológico e prática de atividade física, pode promover a perda de peso a longo prazo.

Apesar do alto consumo de gordura e do excesso de peso, observados neste estudo, a média do valor calórico total de calorias foi baixa (1564_617,83 calorias), conforme também observado por CERVATO et al. (1997) e NAKASATO et al. (2000).

Ao comparar estes resultados com aqueles observados por GALEAZZI (1997), que avaliou o valor calórico da dieta em cinco cidades 
brasileiras (Rio de Janeiro, Campinas, Curitiba, Goiânia e Ouro Preto), a média calórica observada apresenta-se inferior àquela do citado estudo que foi de 2335 calorias na população acima de 46 anos. Os resultados do presente estudo foram semelhantes aos observados por MONTILLA (2001).

Não houve possibilidade de comparar os valores energéticos com o estado nutricional inadequado observado, pois o consumo alimentar fornecido foi habitual e não poderia, portanto, exercer influência direta sobre a prevalência de obesidade observada, uma vez que o ganho de peso é um processo crônico.

Outrossim, a omissão involuntária ou o fornecimento incorreto de informações devido a não familiaridade com o nutricionista, bem como orientação nutricional prévia, fornecida por outros profissionais de saúde ou por pessoas leigas ou, até mesmo, a utilização voluntária de dietas hipocalóricas, podem ter sido a causa do baixo valor calórico observado.

É importante refletir, também, sobre o método utilizado para a coleta dos dados dietéticos.

A história dietética tipo "Burke", apresenta como vantagens a obtenção de um perfil completo de uma dieta atual e elimina variações do dia-a-dia, porém pode haver subestimativa das quantidades de alimentos mencionados, uma vez que esse método depende da memória do 
entrevistado e do conhecimento dos tamanhos de porções de alimentos, o que pode dificultar a coleta de dados e, portanto, fornecer informações inadequadas (NAKASATO et al. 2000; DWYER 2003).

Quanto ao consumo protéico, observou-se diferença significativa entre os grupos etários de 55-65 anos e 65-75 anos, sendo que o grupo etário mais jovem apresentou maior consumo, apesar de não ter sido observada inadequação quanto à distribuição percentual deste nutriente.

MONTILLA (2001) observou o consumo elevado de proteínas no climatério, o que talvez possa sugerir um consumo inadequado crônico que se estende após a menopausa.

O excesso protéico pode aumentar a excreção renal de cálcio, o que pode levar à osteoporose e, portanto, torna-se preocupante uma vez que após a menopausa ocorre perda progressiva de massa óssea (JOHINSTON JR 1994).

Em relação às fibras alimentares, observou-se baixo consumo deste nutriente o que foi semelhante aos resultados observados por FEDERIMANN (1994) e MATTOS \& MARTINS (2000). 
As fibras alimentares estão associadas ao poder de saciedade, pois auxiliam no controle do consumo de alimentos calóricos e, conseqüentemente, na redução de peso (LUDWIG 2000).

Certos tipos de fibras alimentares solúveis, quando consumidas em quantidades adequadas, podem reduzir os niveis de colesterol total e LDL-c por se ligarem aos ácidos biliares, podendo determinar ação semelhante a medicamentos hipolipemiantes (FONSECA et al. 1999).

Em 1994, MONDINI \& MONTEIRO observaram queda no consumo de feijão ao longo das décadas de 70 e 80 , principalmente pelo advento da urbanização e industrialização, o que levou à maior oferta de produtos congelados e semiprontos.

Observou-se também que, entre as mulheres mais idosas, o consumo de fibras alimentares foi significativamente maior, o que talvez possa ser explicado pelas escolhas alimentares "tradicionais" nesta população, a qual inclui, mais comumente, leguminosas na refeição diária.

Outrossim, é importante ressaltar, que o consumo de fibras alimentares observado talvez esteja subestimado, devido às limitações apresentadas pelo banco de dados do programa de computador utilizado para o cálculo do consumo alimentar, o que pode, portanto, ter caracterizado inadequadamente a população deste estudo. 


\section{CONCLUSÕES}

A partir dos resultados obtidos, conclui-se que:

* O estado nutricional, segundo o IMC, está inadequado devido à prevalência de obesidade na população estudada, principalmente na mais jovem, que implica o surgimento de outras doenças crônicas e diminuição da qualidade de vida desta população e explica, ao menos em parte, a ocorrência de DAC.

Houve correlação entre a idade e o IMC.

* A prevalência de diabetes melito e hipertensão arterial sistêmica, na população mais jovem, é acentuada e, prediz o surgimento de sérias complicações metabólicas futuras.

* O uso de hipolipemiantes pela população estudada pareceu ser favorável, pois se observou, principalmente na população mais idosa, discretas alterações no perfil lipêmico, como os níveis de colesterol total e LDL-C, os quais, quando elevados, estão fortemente relacionados com a ocorrência de doenças cardiovasculares.

Não houve correlação entre a "idade", "IMC" e "níveis plasmáticos de lípides", na maioria da população estudada. 
* Inadequação na distribuição percentual de macronutrientes, principalmente gorduras e carboidratos.

Consumo inadequado de fibras alimentares.

* A população mais jovem apresentou consumo maior de proteínas e gorduras, enquanto que a mais idosa maior consumo de fibras alimentares.

* Não houve correlação entre a "idade" e o "consumo de proteínas", "consumo de carboidratos" e "consumo de fibras alimentares".

* Houve correlação entre a "idade" e o "consumo de gorduras" e o "valor calórico total da dieta".

Mediante às inadequações observadas, as quais podem refletir no desenvolvimento de alterações fisiopatológicas que figuram na literatura científica como os principais fatores de risco para DAC, podemos concluir que temos, portanto, indivíduos que já desenvolveram a doença e que continuam perpetuando os fatores de risco que os levaram a ela. 


\section{RECOMENDAÇÕES}

Frente as conclusões anteriores, recomenda-se:

A elaboração de programas de acompanhamento nutricional, antes da instalação da menopausa, com orientações visando a perda de peso de maneira adequada, aliando dieta equilibrada e atividade física regular, a fim de promover a redução e adequado consumo de gorduras, visando a prevenção da doença.

A realização de estudos prospectivos, bem conduzidos, com coleta de dados dietéticos detalhada, visando análise mais fidedigna do consumo alimentar na pós-menopausa. 


\section{REFERÊNCIAS BIBLIOGRÁFICAS}

1. [ADA]. AMERICAN DIABETES ASSOCIATION. The Expert Committee on the Diagnosis and Classification of Diabetes Mellitus. Report of the Expert Committee on the Diagnosis and Classification of Diabetes Mellitus. Diabetes Care 2002; 25(supl 1): S5-S20.

2. [AHA]. AMERICAN HEART ASSOCIATION. 2001 Heart and stroke stastical update. Dallas:AHA; 2000.

3. [AHA]. AMERICAN HEART ASSOCIATION. Risk factors and coronary heart disease. [texto on line] 2001. Disponivel em <http:// www.americanheart.org/Heart and Stroke A Z Guide/riskfact.html> [2001 Mar 23].

4. ALDRIGHI JM. Balanço risco/benefício da terapêutica de reposição hormonal: direções para o futuro. Rev Soc Cardiol Estado de São Paulo 1996; 6(6): 734-8.

5. ALOYSIO D, GAMBACCIANI M, MESCHIA M, PANSINI F, MODENA AB, BOLIS PF et al. The effect of menopause on blood lipid and lipoprotein levels. Atherosclerosis 1999; 147: 147-53. 
6. AMIGONI S, MORELLI P, PARAZZINI F, CHATENOUD L. Determinants of elevated blood pressure in women around menopause: results from a cross-sectional study in Italy. Maturitas 1999; 34: 25-32.

7. ARMAGANIJAN D \& BATLOUNI M. Impacto dos fatores de risco tradicionais. Rev Soc Cardiol Estado de São Paulo 2000; 10(6): 68693.

8. AZEVEDO AC \& SEKEFF J. Cardiologia clínica São Paulo:Sarvier; 1994. Doenças das artérias coronárias. p. 69-92.

9. BERTOLAMI MC, FALUDI AA, LATORRE MRDO, ZAIDAN FO T. Perfil lipídico de funcionários de indústria metalúrgica e sua relação com outros fatores de risco. Arq Brasil Cardiol 1993; 60: 293-9.

10. BICKEL PJ \& DOKSUM KA. Mathematical statistics - Basic ideas and selected topics New York:Ed Holden-Day; 1977. p. 153-91.

11. BIFFI EFA. O fenômeno da menopausa: uma perspectiva de compreensão. Ribeirão Preto; 1991. [Dissertação de Mestrado - Escola de Enfermagem da USP].

12.BONDUKI CE, BARACAT ED, HAIDAR MA, LIMA GR. Climatério e doenças cardiovasculares. [texto on line] 2001. Disponível em <URL: 
http:// www.dr-online.com.br/revistas/revista-fac-3-cardiovascularesmateria.html> [2001 Ago 2].

13.BYYNY RL \& SPEROFF L. A clinical guide for the care of older women: primary and preventive care. $2^{\text {nd }}$ ed. Baltimore:Williams \& Wilkins; 1996. The rectangularization of life; p. 1-19.

14. CARAMELLI B. Tendências seculares da população com doença isquêmica do coração internada em hospital especializado. São Paulo; 1997. [Tese de Livre-Docência - Faculdade de Medicina da USP].

15. CARDOSO E, ISOSAKI M, NAZIMA MKN, NAKASATO M. Anamnese e diagnóstico na assistência nutricional ao cardiopata. Rev Soc Cardiol Estado de São Paulo 1997; 7(5-supl A); 63-8.

16. CARVALHO FILHO ET, ALENCAR YMG, LIBERMAN S. Fatores de risco de aterosclerose na mulher após a menopausa. Arq Bras Cardiol 1996; 66(1): $37-48$.

17. CARVALHO KMB. Obesidade. In: LÍLIAN CUPPARI (coord) Guias de medicina ambulatorial e hospitalar - Unifesp/Escola Paulista de Medicina - Nutrição - Nutrição clínica no adulto. São Paulo:Manole; 2002. p.131-50. 
18. CASTELLI WP. Menopause and cardiovascular disease. In: ESKIN BA. The menopause: comprehensive management New York:McGraw-Hill; 1994. p. 117-36.

19. CERVATO AM, MAZZILLI RN, MARTINS IS, MARUCCI MFN. Dieta habitual e fatores de risco para doenças cardiovasculares. Rev Saúde Pública 1997; 31 (3): 227-35.

20. CHIAMVIMONVAT V \& STERNBERG L. Coronary artery disease in women. Can Fam Physician 1998; 44: 2709-17.

21. COLDITZ GA, WILLETT WC, STAMPFER MJ, ROSNER B, SPEIZER FE, HENNEKENS CH. Menopause and the risk of coronary heart disease in women. N Engl J Med 1987; 316(18): 1105-10.

22. COSTA MPF, PEIXOTO MSP, URRUTIA GIDCE. Doença cardiovascular e mulher: reflexão para a enfermeira. Rev Soc Cardiol Estado de São Paulo 1996; 6(Supl A): S1-S5.

23. COSTA NETO PLO. Estatística São Paulo:Ed Edgard Blucher Ltda; 1977. p. 78.

24. COSTA RP, MENENDEZ G, BRICARELLO LP, ELIAS MC, ITO M. Óleo de peixe, fitoesteróis, soja e antioxidantes: impacto nos lípides e na 
aterosclerose Rev Soc Cardiol Estado de São Paulo 2000; 10(6): 819827.

25. CUNNINGHAM SG. Women's heart health - an intagrated approach to prevention. Can J Cardiovasc Nurs 1998; 9(3): 28-37.

26. CUTSON TM \& MEULEMAN E. Managing menopause. Am Family Physician [serial online] 2000. [12 screens] Avaliable from: < URL: http://www.aafp.org/afp/20000301/1391.html> [2001 Jan 11].

27. DE HOOG S. Avaliação do estado nutricional. In: MAHAN LK \& ESCOTTSTUMP Krause: alimentos, nutrição \& dietoterapia $9^{a}$ ed. São Paulo: Rosa; 1998.

28.DESPRÉS J-P, LEMIEUX I, PRUD'HOMME D. Treatment of obesity: need to focus on high risk abdominally obese patients. BMJ 2001; 322: 716-20.

29.DUBNOV G, BRZEZINSKI A, BERRY EM. Weight control and the management of obesity after menopause: the role of physical activity. Maturitas 2003; 44: 89-101. 
30. DWYER J. Avaliação do consumo alimentar. In: SHILS ME, OLSON JA, SHIKE M, ROSS AC. Tratado de nutrição moderna na saúde e na doença. $9^{a}$ ed. São Paulo:Manole; 2003. p.1001-26.

31. ECKEL RH. Obesity in heart disease. Circulation 1997; 96: 3248-50.

32. ELL E, CAMACHO LAB, CHOR D. Perfil antropométrico de funcionários de banco estatal no Estado do Rio de Janeiro/Brasil: I - Índice de massa corporal e fatores sócio-demográficos. Cad Saúde Pública 1999; 15(1): $113-21$.

33. FAVARATO MECS. A mulher coronariopata no climatério após a menopausa: implicações na qualidade de vida. São Paulo; 2000. [Dissertação de Mestrado - Faculdade de Saúde Pública da USP].

34.FEDERMANN M. Conhecimentos e práticas alimentares de indivíduos diabéticos não insulino-dependentes São Paulo; 1994. [Dissertação de Mestrado - Faculdade de Saúde Pública da USP].

35. FELDMAN EB. Nutritional needs of climateric women. In: NOTELOVITZ M, KEEP PA. The climateric in perspective. Lancaster:MTP Press; 1986. p.27-40. 
36. FERREIRA C. Doenças cardiovasculares, aterosclerose e fatores de risco [texto on line] 2001. Disponivel em < URL: http://www.unifesp.br/dmed/cardio/ch/cardio.htm> [2001 Nov 2].

37. FONSECA FAH, ELIAS MC, MENENDEZ G, ITO MT, BARBOSA LA. Modificações dos hábitos de vida e outras opções terapêuticas. Rev Soc Cardiol Estado de São Paulo 1999; 9(1): 77-82.

38. FONSECA MJM, CHOR D, VALENTE JG. Hábitos alimentares entre funcionários de banco estatal: padrão de consumo alimentar. Cad Saúde Pública 1999; 15(1): 29-39.

39. FUNDAÇÃO IBGE. Censo demográfico de 1991 e 2000 e contagem populacional de 1996. Rio de Janeiro; 2000.

40.GAEDE P, VEDEL P, PARVING HH, PEDERSON O. Intensified multifactorial intervention in patients with type 2 diabetes mellitus and microalbuminuria: The steno type 2 randomised study. Lancet 1999; 353: 617-22.

41. GALEAZZI MAM (org). Estudo multicêntrico sobre consumo alimentar. Revista do Núcleo de Estudos e Pesquisas em Alimentação/UNICAMP. Vol Especial - Ministério da Saúde; 1997. 
42. GEBARA OCE. Terapêutica de reposição hormonal: efeitos vasculares e hemostáticos. Rev Soc Cardiol Estado de São Paulo 1996; 6(6): 72430.

43. GIANNINI SD. Aterosclerose - dislipidemias: clínica e terapêutica: fundamentos práticos. São Paulo:BG Cultural; 1998.

44. GIANNINI SD. História natural da aterosclerose. Rev Soc Cardiol Estado de São Paulo 2000; 10(6): 677-85.

45. GORODESKI GI. Update on cardiovascular disease in post-menopausal women. Best Practice \& Research Clinical Obstetrics and Gynaecology 2002; 16(3): 329-355.

46. GUIMARÃES AC, LIMA M, MOTA E, LIMA JC, MARTINEZ T, CONTI FILHO A et al. The cholesterol level of a selected salaried population: biological and socioeconomic influences. CVD Prevention 1998; 1: 30617.

47. GUYTON AC. Fisiologia humana e mecanismos das doenças. $5^{\mathrm{a}}$ ed. Rio de Janeiro: Guanabara\&Koogan; 1993. Fisiologia feminina antes da gravidez e os hormônios femininos; p 520-8. 
48. HEGG R, MELO NR, PINOTTI M. Síndrome do climatério - conceito, importância e epidemiologia. Rev Bras Med 1994; 51(3): 327-34.

49. HILL JO, MELANSON EL, WYATT HT. Dietary fat intake and regulation of energy balance: implication for obesity. J Nutr 2000; 130: 284S-8S.

50. HJERMANN I, BYRE KV, HOLME I, LEREN P. Effect of diet and smoking intervention on the incidence of coronary heart disease. Report from the Oslo Study of a randomized trial in health men. Lancet $1981 ; 2: 1303-10$.

51. HOLLANDER M \& WOLF DA. Nonparametric statistical methods. New York:John Wiley \& Sons; 1973.

52. HU FB, STAMPFER MJ, MANSON JE, RIMM E, COLDITZ GA, ROSNER BA et al. Dietary fat intake and the risk of coronary heart disease in women. N Engl J Med 1997; 337(21): 1491-9.

53. HYPERTENSION IN DIABETES STUDY GROUP. HDS 1: Prevalence of hypertension in newly presenting type 2 diabetic patients and the association with risk factors for cardiovascular and diabetic complications. J Hypertens 1993; 11: 309-17.

54. [IMNA] INSTITUTE OF MEDICINE OF NATIONAL ACADEMIES. Panel on Macronutrients, Panel on the Definition of Dietary Fiber, Subcommittee 
on Upper Reference Levels of Nutrients, Subcommittee on Interpretation and Uses of Dietary Reference Intakes, and the Standing Committee on the Scientific Evaluation of Dietary Reference Intakes.Dietary reference intakes for energy, carbohydrate, fiber, fat, fatty acids, cholesterol, protein, and amino acids (macronutrients). Washington (DC): The National Academic Press; 2002.

55. JACOBSEN BK, KNUTSEN SF, FRASER GE. Age at natural menopause and total mortality and mortality from ischemic heart disease: The adventist health study. J Clin Epidemiol 1999; 52(4): 303-7.

56. JOHNSTON JR CC. Osteoporosis. In: ESKIN BA. The menopause: Comprehensive management $3^{\text {th }}$ ed. New York: MacGraw Hill; 1994. p. 103-17.

57. KANNEL WB, CASTELLI WP, GORDON T. Cholesterol in the prediction of atherosclerotic disease. New perspectives based on the Framingham Study. Ann Int Med 1979; 90: 85-91.

58. KEYS A. The diet and 15-year death rate in the seven countries study. Am J Epidemiol 1986; 124: 903-15. 
59. KO GTC, CHAN JCN, WOO J, LAU EMC, YEUNG VTF, CHOW C et al. The effect of age on cardiovascular risk factors in Chinese women. Intern J Cardiol 1997; 61: 221-7.

60.KRAUSS RM, ECKEL RH, HOWARD B. AHA Dietary Guidelines: revision 2000: A statement for healthcare professionals from the Nutrition Committee of the American Heart Association. Circulation 2000; 102: 2284-99.

61. KRUMMEL D. Nutrição na doença cardiovascular. In: MAHAN LK \& ESCOTT-STUMP S. Krause - Alimentos, nutrição \& dietoterapia. $9^{a}$ ed. São Paulo: Roca; 1998. p. 543-6.

62. LEGATO MJ. Cardiovascular disease in women: gender-specific aspects of hypertension and the consequences of treatment. $\mathbf{J}$ Women Health 1998; 7(2): 199-209.

63. LEHTO S, RÖNNEMAA T, HAFFNER SM, KALLIO V, LAAKSO M. Dyslipidemia and hyperglycemia predict coronary heart disease events in middle-aged patients with NIDDM. Diabetes 1997;46:1354-9.

64.LEMIEUX S, PRUD'HOMME D, TREMBLAY A, BOUCHARD C, DESPRÉS JP. Anthropometric correlates to changes in visceral adipose 
tissue over 7 years in women. Int J Obes Relat Metabol Disord 1996; 20: 618-24.

65. LESSA I, MENDONÇA GAS, TEIXEIRA MTB. Noncommunicable chronic diseases in Brazil: from frisk factors to social impact. Bol Oficina Sanit Panam 1996; 120: 389-413.

66. LICHTENSTEIN AH \& van HORN L. Very low fat diets. Circulation 1998; 98: $935-9$.

67. LIMA JAC \& NUSSBACHER A. O coração da mulher é diferente? Rev Soc Cardiol Estado de São Paulo 1996; 6(6): 704-6.

68. LOTUFO PA. Doenças cardiovasculares no Brasil: por que altas taxas de mortalidade entre as mulheres? Rev Soc Cardiol Estado de São Paulo 1996; 6: 667-71.

69. LOTUFO PA. Mortalidade precoce por doenças do coração no Brasil. Comparação com outros países. Arq Bras Cardiol 1998; 70(5): 321-5.

70. LUDWIG DS. Dietary glycemic index and obesity. J Nutr 2000; 130: 280S-3S. 
71. LUZ PL, CARVALHO MEA, CARDOSO RHA, GALLUCI SDP, PILEGGI F. Incidência de dislipidemia e sua relação com doença arterial coronária em populações brasileiras. Arq Bras Cardiol 1990; 54: 257-64.

72.LUZ PL \& SANTOS RD. Menopausa e fatores de risco para doença coronariana. Rev Ass Med Brasil 1994; 40(2): 121-4.

73. MacINTOSH C, MORLEY JE, CHAPMAN IM. The anorexia of aging. Nutrition 2000; (16): 983-95.

74. MCCRORY MA, FUSS PJ, MCCALLUM JE, YAO M, VINKEN AG, HAYS NP et al. Dietary variety within food groups: association with energy intake and body fatness in men and women. Am J Clin Nutr 1999; 69: 440-7.

75. MARTINEZ JA. Body-weight regulation: causes of obesity. Proceedings of the Nutr Soc 2000; 59 : 337-45.

76. MARTINS IS, MARUCCI MFN, CERVATO AM, OKANI ET, MAZZILLI RN CASAJUS MI. Doenças cardiovasculares ateroscleróticas, dislipidemias, hipertensão e diabetes melito em população da área metropolitana da Região Sudeste do Brasil: II - Dislipidemias. Rev Saúde Pública 1996; 30: $75-84$. 
77. MARUCCI MFN \& GOMES MMBC. Interação droga-nutriente em idosos. In: Papaléo Netto M. (org). Gerontologia. São Paulo:Atheneu; 1997. p. 273-83.

78. MATTOS LL \& MARTINS IS. Consumo de fibras alimentares em população adulta. Rev Saúde Pública 2000; 34(1): 50-5.

79. MELO NR, POMPEI LM, WEHBA S, FERNANDES CE \& RAMOS LO. Efeitos colaterais e riscos da terapia de reposição hormonal. Rev Soc Cardiol Estado de São Paulo 1996; 6(6): 731-3.

80. [MS]. MINISTÉRIO DA SAÚDE. Coordenação de doenças cardiovasculares. Doenças cardiovasculares no Brasil (Sistema Único de Saúde - SUS). Brasília; 1993. Fatores de risco para doenças cardiovasculares. p. 12-21.

81. [MS]. MINISTÉRIO DA SAÚDE. Departamento de assistência e promoção à saúde e coordenação materno-infantil. Assistência ao climatério. Brasília (DF); 1994.

82. [MS]. MINISTÉRIO DA SÁUDE. Informações hospitalares [relatório on line] 2000. Disponivel em <URL: http://www.datasus.gov.br> [2001 Jan 30]. 
83. MONDINI L \& MONTEIRO CA. Mudanças no padrão de alimentação da população urbana brasileira (1962-1988). Rev. Saúde Pública 1994; 28(6): 433-9.

84. MONTEIRO CA, CONDE WL, POPKIN BM. Independent effect of income and education on the risk of obesity in the Brasilian adult population. $\mathbf{J}$ Nutr 2001; 131: 881S-886S.

85. MONTILLA RNG. Avaliação do estado nutricional e do consumo alimentar de mulheres no climatério em um centro de saúde-escola. São Paulo; 2001. [Dissertação de Mestrado - Faculdade de Ciências Farmacêuticas, Faculdade de Economia, Administração e Contabilidade e Faculdade de Saúde Pública (PRONUT) da USP].

86. NAGATA C, TAKATSUKA N, INABA S, KAWAKAMI N, SHIMIZU $H$. Association of diet and other lifestyle with onset of menopause in Japanese women. Maturitas 1998; 29: 105-13.

87. NAKASATO M, MACEDO A, ÁVILA ALvE, ISOSAKI M, PORTES RGO. Perfil nutricional dos pacientes atendidos no ambulatório de nutrição. Rev Soc Cardiol Estado de São Paulo 2000; 10(4): 13-22. 
88. [NAMS]. THE NORTH AMERICAN MENOPAUSE SOCIETY. Menopause core curriculum study guide - Section A: Introducion. Ohio; 2002.

89. [NIH]. NATIONAL INSTITUTE OF HEALTH. National Heart, Lung, and Blood Institute. Obesity Education Initiave. Expert Panel on the Indentification, Evaluation, and Treatment of Overweight and Obesity in Adults. Washington (DC); 1998.

90. NÓBREGA JF. Distúrbios da nutrição Rio de Janeiro:Revinter; 1998. Cardiovasculares. p. 452-56.

91. O'BRIEN T \& NGUYEN TT. Lipids and lipoproteins in women. Mayo Clin Proc 1997; 72(3): 235-44.

92. OLIVEIRA A, CARDOSO E, ISOSAKI M. Avaliação do risco de desnutrição de idosos com insuficiência cardíaca internados em hospital especializado em cardiologia. Rev Bras Nutr Clin 2003; 18(1): 21-5.

93. OLIVEIRA SF, LUZ PL, RAMIRES JAF. Disfunção vascular no diabete melito. Rev Soc Cardiol Estado de São Paulo 1998; 8(5): 892-901. 
94. OMRAN ML \& MORLEY JE. Assessment of protein energy malnutrition in older persons, part I: history, examination, body composition, and screening tools. Nutrition 2000; (16): 50-63.

95. PANZRAM G. Mortality and survival in Type 2 (non-insulin-dependent) diabetes mellitus. Diabetologia 1987;30:123-31.

96.PASQUALI R, CASIMIRRI F, PASCAL G, TORTELLI O, MORSELLI LABATE A, BERTAZZO D et al. Influence of menopause on blood cholesterol levels in women: the role of body composition, fat distribution and hormonal milieu. Virgilio Menopause Health Group. J Intern Med 1997; 241(3): 195-203.

97.PEETERS A, MAMUN AA, WILLEKENS $F$, BONNEUX L. A cardiovascular life history. Eur Heart J 2002; 23: 458-66.

98. PHILIPPI ST. Virtual Nutri: Sistema de Análise Nutricional [programa de computador], versão 1.0 for Windows. São Paulo. Departamento de Nutrição/Faculdade de Saúde Pública/Universidade de São Paulo; 1996.

99. PIETINEN P, VARTIAINEN E, SEPPANEN R, ARO A, PUSKA P. Changes in diet in Finland from 1972 to 1992: impact on coronary heart disease risk. Prev Med 1996; 25(3): 243-50. 
100. PINOTTI JA \& FONSECA AM. Saúde da mulher. São Paulo: Contexto; 1998. Doenças crônico-degenerativas; p. 118-25.

101. PI-SUNYER FX. Obesidade. In: SHILS ME, OLSON JA, SHIKE M \& ROSS AC. Tratado de nutrição moderna na saúde e na doença. $9^{a}$ ed. São Paulo:Manole; 2003.p.1493-1518.

102. PORRINI M. Relation between diet composition and coronary heart disease risk factors. J Epidemiol Community Health 1991; 45(2): 14851.

103. POSNER BM, CUPPLES LA, MILLER DR, COBB JL, LUTZ KJ, D'AGOSTINHO RB. Diet, menopause, and serum cholesterol levels in women: The Framingham Study. Am Heart J 1993; $125(2$ pt 1): 483-9.

104. POURCHET-CAMPOS MA. Fibra dietética. In: Dutra-de-Oliveira JE \& Marchini JS (org). Ciências nutricionais São Paulo:Sarvier; 1998. p. 209-215.

105. READ C. Tratando a menopausa: um guia prático para a terapia de reposição hormonal. [texto on line] 2000. [19 telas] Disponível em: <URL: http://www.climaterio.org/livro.html> [2001 Mar 22]. 
106. ROCHA CR, SIQUEIRA PRA, OLIVEIRA PRF, MOURA MAV, SPINDOLA T. A enfermagem e a saúde da mulher: questões de gênero e sociopolíticas. Esc Anna Nery Rev Enferm 2000; 4(1): 105-14.

107. ROLLS BJ. Do chemosensory changes influence food intake in the elderly? Physiology \& Behavior 1999; 66(2): 193-7.

108. ROSNER B. Fundamentals of biostatistics $2^{\text {nd }}$ ed. Boston:PWS Publishers; 1986.

109. [SBC]. SOCIEDADE BRASILEIRA DE CARDIOLOGIA. III Diretrizes Brasileiras sobre Dislipidemias e Diretriz de Prevenção da Aterosclerose do Departamento de Aterosclerose da Sociedade Brasileira de Cardiologia. Arq Bras Cardiol 2001; 77 (supl III): 1-48.

110. [SBD]. SOCIEDADE BRASILEIRA DE DIABETES. Diagnóstico e classificação do diabetes mellitus e tratamento do diabetes mellitus tipo 2. São Paulo; 2000.

111. $[S B H], \quad[S B C], \quad[S B N] . \quad$ SOCIEDADES BRASILEIRAS DE HIPERTENSÃO, CARDIOLOGIA E NEFROLOGIA. IV Diretrizes Brasileiras de Hipertensão Arterial. São Paulo; 2002. 
112. SCHENCK-GUSTATSON K. Risk factors for cardiovascular disease in women: assessment and management. Eur Heart J 1996; 17(supl D): S2-S8.

113. SECRETARIA DE SAÚdE DO ESTADO DE SÃO PAULO. Grupo técnico de informações de saúde - CIS. Mortalidade geral pelos cinco principais grupos de causa (CID 10) segundo região de saúde (DIR). São Paulo; 1998 [relatório on line]. Disponível em < URL: http://www.saude.sp.gov.br/Dsaude/Morb mor/M geral/Html/Mg cf.html/> [2000 Jun 1].

114. SHELLEY JM, GREEN A, SMITH AMA, DUDLEY E, DENNERSTEIN L, HOPPER J et al. Relationship of endogenous sex hormones to lipids and blood pressure in mid-aged women. Ann Epidemiol 1998; 8: 39-45.

115. SIMONS LD. Interrelations of lipids lipoproteins with coronary artery disease mortality in 19 countries. Am J Cardiol 1986; 27: 50-106.

116. SIMOPOULOS AP. Essential fatty acids in health and chronic disease. Am J Clin Nutr 1999; 70(suppl): 560S-9S.

117. SIZER FS \& WHITNEY EN. Nutrição: conceitos e controvérsias. Barueri:Manole; 2003. Os lipídeos: gorduras, óleos, fosfolipídeos e esteróis; p. 133-74. 
118. STAMLER J. Epidemic obesity in the United States. Arch Intern Med 1993; 153: 1040-44.

119. STEVENSON JC, CROOK D, GODSLAND IF. Influence of age and menopause on serum lipids and lipoproteins in healthy women. Atherosclerosis 1993; 98(1): 83-90.

120. STONE NJ, CHAIR MD, NICOLOSI RJ. Summary of the scientific conference on the efficacy of hypocholesterolemic dietary interventions. Circulation 1996; 94: 3388-91.

121. TIMERMAN A, SANTOS RD, SOUZA MFM, SERRANO JR CV. Aspectos epidemiológicos das doenças cardiovasculares em nosso meio: tendência da mortalidade por doença isquêmica do coração no Brasil de 1979 a 1996. Rev Soc Cardiol Estado de São Paulo 2001; 11(4): 71523.

122. TRÉMOLLIĖRES FA, POILLES J-M, CAUNEILLE C, RIBOT C. Coronary heart disease risk factors and menopause: a study in 1684 French women. Atherosclerosis 1999; 142(2): 415-23.

123. TRICHOPOULOU A \& LAGIOU P. Healthy tradicional mediterranean diet: an expression of culture, history, and lifestyle. Nutr Rev 1997; 55(11 pt 1): 383-9. 
124. TURPEINEN O, KARVONEN MJ, PEKKARINEN M. Dietary prevention coronary heart disease. The Finish Mental Hospital Study. Int J Epidemiol 1979; 8: 99.

125. VERAS RP, RAMOS LR, KALACHE A. Crescimento da população idosa no Brasil: transformações e conseqüências na sociedade. Rev. Saúde Pública 1987; 21(3): 225-33.

126. WEISBURGER JH. Eat to live, not live to eat. Nutrition 2000; 16: 767 73.

127. WELTY FK. Women and cardiovascular risk. Am J Cardiol 2001; 88(suppl): 48J-52J.

128. WENGER NK. Hypertension and other cardiovascular risk factors in women. Am J Hypertens 1995; 8(12 pt 2): 94S-9S.

129. WENGER NK. Epidemiology of coronary heart disease in women. Rev Soc Cardiol Estado de São Paulo 1996; 6(6): 672-80.

130. WILLIAMS SR. Fundamentos de nutrição e dietoterapia $6^{a}$ ed. Porto Alegre:Artes Médicas; 1997. Doenças cardíacas, dos vasos sangüíneos e pulmonares; p. 387-414. 
131. [WHO] WORLD HEALTH ORGANIZATION. Consultation on Obesity. Obesity - Preventing and managing the global epidemic (Report). Geneva; 1997.

132. [WHO] WORLD HEALTH ORGANIZATION. Report of a WHO Consultation. Definition, diagnosis and classification of diabetes mellitus and its complications. Part 1: Diagnosis and classification of diabetes mellitus. Geneva;1999.

133. WU S, CHOU P, TSAI S. The impact of years since menopause on the development of impaired glucose tolerance. J Clin Epidemiol 2001; 54: $117-20$.

134. YAMAMOTO A, HORIBE $\mathrm{H}$, MABUCHI H, KITA T, MATSUZAWA Y, SAITO $Y$ et al. Analysis of serum lipid levels in Japanese men and women according to body mass index. Increase in risk of atherosclerosis in postmenopausal women. Atherosclerosis 1999; 143: 55-73. 
Anexos 


\section{ANEXO 1 \\ AprovaçÃo da Comissão Científica e de ÉticA do InSTITUTO do CORAçÃo do HOSPITAL dAS CLÍNICAS - FMUSP}

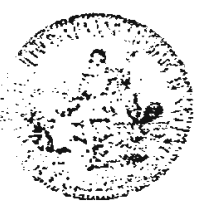

Niem.CC.895/02

na. Sra.

Eisabeth Cardoso

\author{
INSTITUTO DO CORAÇĀO \\ (Fundaçăo E J Zerbinu) \\ Hospital das clinicas
}

Faculdade de Medicina da Universidade de Săo Paulo

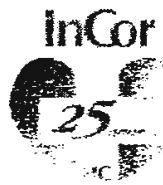

InCor

-

São Paulo, 17 de outubro de 2002.

A Comissắa Cientifica e de Ética do Ir stituto do Coração, apreciou e aprovou na sessāo 417/02/17 de 17/10/2002, Frotocolo de Pesquisa SDC - 2112/02/119 - "Aspectos nutricionais e fatores de risco em mulheres pós-menopausa com doença arterial coronariana", e foi o seguinte o parecer do relator. "Aprovado no mérito cientifico, sem ônus para a Instituição".

Atenciosamente,

Selma Cristina Quaia

Secretária da Comissão Científica e de Ética InCoriHC/FMUSP

ScQ/mva

Av. Dr. Eneas de Carvalha Agular, 44 - CEP: C6403-900 - Sato Pauto - SP - Brasi - Fone (011) 3000.5000 


\title{
ANEXO 2
}

\section{Aprovação da Comissão de Ética para ANÁlise de Projetos de Pesquisa - CAPPESQ DA DIRETORIA CLÍNICA do HOSPITAL dAS CLÍNICAS - FMUSP}

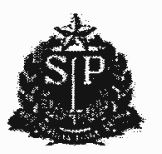

\author{
HOSPITAL DAS CLINICAS \\ DA FACULDADE DE METICINA DA UNWERSIDADE DE SAOO PAULLO \\ CAIXA POSTAL, 8091 - SRO PAULO-BRASIL
}

\section{DIRETORIA CLÍNICA}

\section{Comissão de Ética para Análise de Projetos de Pesquisa}

\section{APROVACẼOO}

A Comissão de Ética para Análise de Projetos de Pesquisa - CAPPesq da Diretoria Clínica do Hospital das Clínicas e da Faculdade de Medicina da Universidade de São Paulo, em sessấo de 20.11.02, APROVOU o Protocolo de Pesquisa no 891/02, intitulado: "Aspectos nutricionais e fatores de risco em mulheres pós-menopausa com doença arterial coronariana", apresentado pelo Departamento de CÁRDIO-PNEUMOLOGIA, bem como o Termo de Consentimento Livre e Esclarecido.

Pesquisador(a) Responsável: SRA. ELISABETH CARDOSO

Pesquisador(a) Executante: SRA. APARECIDA DE OLIVEIRA

CAPPesq, 20 de Novembro de 2002

PROF. DR. JORGE KALIL FTLHO Presidente da Comissão de Ética para Análise de Projetos de Pesquisa

OASERVACAOA: Cabe ao pesquisador elaborar a apresentar d CAPPesq, os relatórios partciois e final sobre a pesquisa (Resoluçäo do Conselho Nacional de Saúde $n^{\circ} 196$, de 10.10.1996, inciso IX.2, letra " $c$ "). 
ANEXO 3

VALORES DE REFERÊNCIA DE LÍPIDES PARA INDIVÍDUOS

ACIMA DE 20 ANOS DE IDADE

\begin{tabular}{|c|c|c|}
\hline Lípides & Valores $(\mathrm{mg} / \mathrm{dL})$ & Categoria \\
\hline Colesterol Total & $\begin{array}{c}<200 \\
200-239 \\
\geq 240\end{array}$ & $\begin{array}{c}\text { Ótimo } \\
\text { Limítrofe } \\
\text { Alto }\end{array}$ \\
\hline LDL-c & $\begin{array}{c}<100 \\
100-129 \\
130-159 \\
160-189 \\
\geq 190\end{array}$ & $\begin{array}{c}\text { Ótimo } \\
\text { Desejável } \\
\text { Limítrofe } \\
\text { Alto } \\
\text { Muito Alto }\end{array}$ \\
\hline HDL-C & $\begin{array}{l}<40 \\
>60\end{array}$ & $\begin{array}{c}\text { Baixo } \\
\text { Alto }\end{array}$ \\
\hline TG & $\begin{array}{c}<150 \\
150-200 \\
200-499 \\
\geq 500\end{array}$ & $\begin{array}{c}\text { Ótimo } \\
\text { Limítrofe } \\
\text { Alto } \\
\text { Muito Alto }\end{array}$ \\
\hline
\end{tabular}

Fonte: [SBC]. SOCIEDADE BRASILEIRA DE CARDIOLOGIA 2001. 


\section{ANEXO 4}

\section{AnAmnese e Diagnóstico (anverso)}

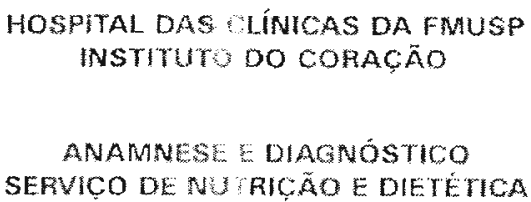

ANAMNESE DIAGNOSTICO SERVICO DE NUTRICÃO E DIETEMCA

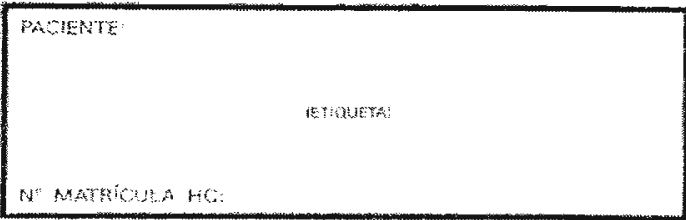

\begin{tabular}{|c|c|c|c|c|c|}
\hline 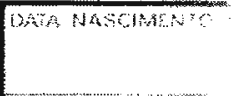 & Sis i & FEO AMALL & $\begin{array}{r}\text { AIOUTAA AT AAt } \\
\mathrm{cm}\end{array}$ & $\begin{array}{l}\text { OLCUNFER:NCLA } \\
\text { pUN:TO }\end{array}$ & POSO ULEAEL \\
\hline WWLE MASSAR COH & WATHA & WWLAOAO AEOOWE. & WHAPRI IH AOW: & & \\
\hline
\end{tabular}

ALIMENTACÃO ATUAL

prefrnenomoning

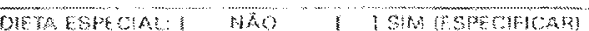

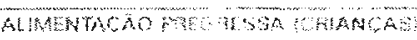

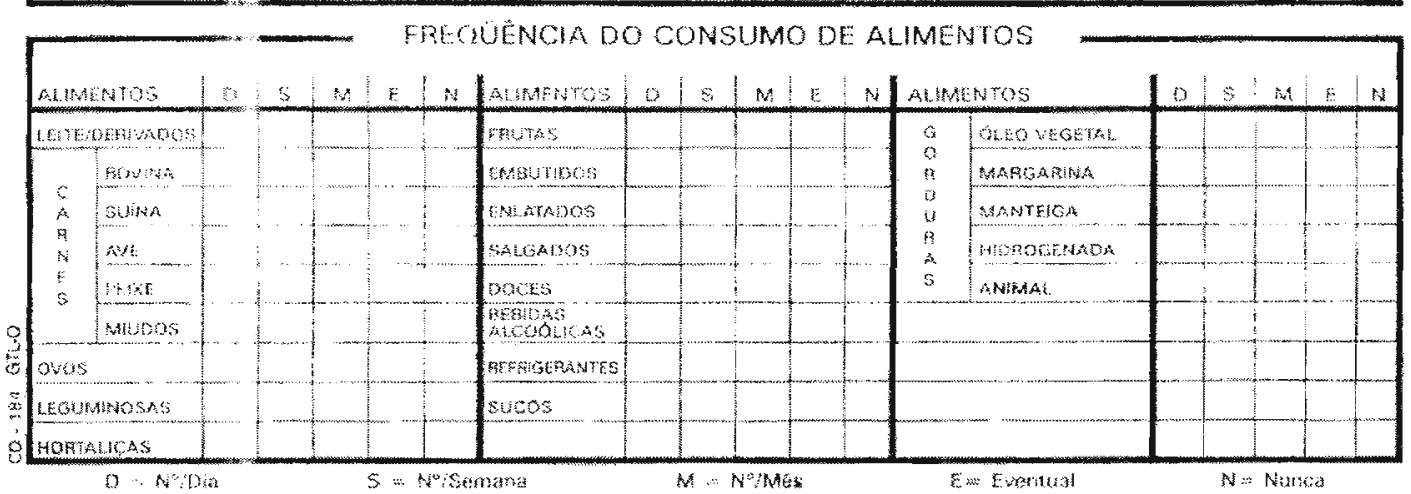

Fonte: CARDOSO E et al. 1997. 
AnAmnese e Diagnóstico (verso)

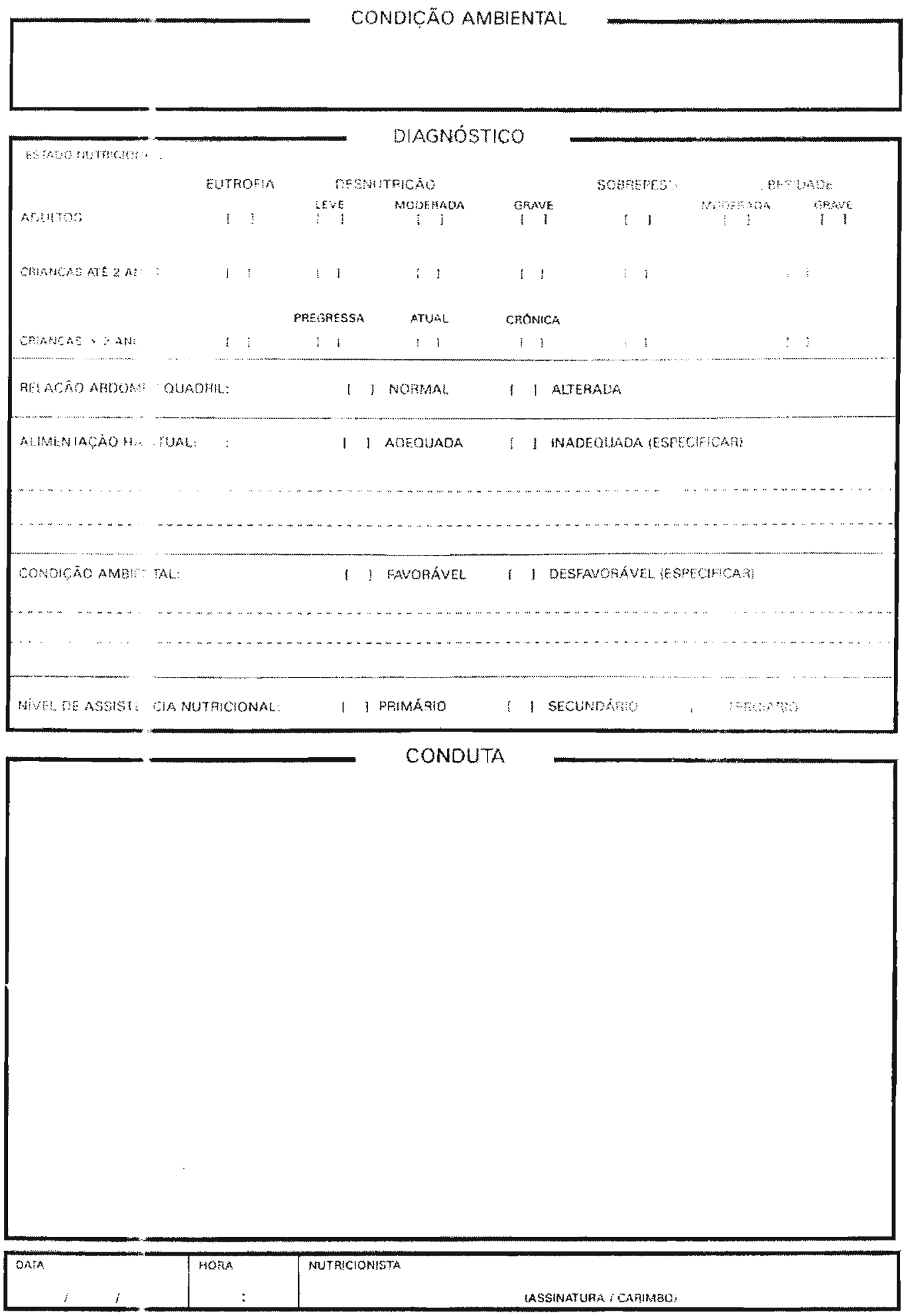

Fonte: CARDOSO E et al. 1997. 